A]1, 100990085

NATL INST OF STANDARDS \& TECH R.I.C.

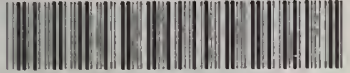

A11100990085

INBS monograoh

QC100 .U556 V72-79:1964-67 C.1 NBS-PUB-C 



$$
\text { an. }
$$




NBS MONOGRAPH 72

Mational Eurreau of Standards

JUL

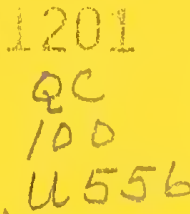

Curves of Input Impedance Change

Due to Ground for Dipole Antennas

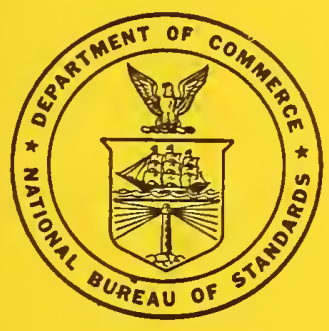

U.S. DEPARTMENT OF COMMERCE

NATIONAL BUREAU OF STANDARDS 


\section{THE NATIONAL BUREAU OF STANDARDS}

\section{Functions and Activities}

The functions of the National Bureau of Standards include the development and maintenance of the national standards of measurement and the provision of means and methods for making measurements consistent with these standards; the determination of physical constants and properties of materials; the development of methods and instruments for testing materials, devices, and structures; advisory services to government agencies on scientific and technical problems; invention and development of devices to serve special needs of the Government; and the development of standard practices, codes, and specifications, including assistance to industry, business and consumers in the development and acceptance of commercial standards and simplified trade practice recommendations. The work includes basic and applied research, development, engineering, instrumentation, testing, evaluation, calibration services, and various consultation and information services. Research projects are also performed for other government agencies when the work relates to and supplements the basic program of the Bureau or when the Bureau's unique competence is required. The scope of activities is suggested by the listing of divisions and sections on the inside of the back cover.

\section{Publications}

The results of the Bureau's research are published either in the Bureau's own series of publications or in the journals of professional and scientific societies. The Bureau itself publishes three periodicals available from the Government Printing Office: The Journal of Research, published in four separate sections, presents complete scientific and technical papers; the Technical News Bulletin presents summary and preliminary reports on work in progress; and Central Radio Propagation Laboratory Ionospheric Predictions provides data for determining the best frequencies to use for radio communications throughout the world. There are also seven series of nonperiodical publications: Monographs, Applied Mathematics Series, Handbooks, Miscellaneous Publications, Technical Notes, Commercial Standards, and Simplified Practice Recommendations.

A complete listing of the Bureau's publications can be found in National Bureau of Standards Circular 460, Publications of the National Bureau of Standards, 1901 to June 1947 (\$1.25), and the Supplement to National Bureau of Standards Circular 460, July 1947 to June 1957 $(\$ 1.50)$, and Miscellaneous Publication 240, July 1957 to June 1960 (includes Titles of Papers Published in Outside Journals 1950 to 1959) (\$2.25); available from the Superintendent of Documents, Government Printing Office, Washington, D.C., 20402. 


\title{
Curves of Input Impedance Change \\ Due to Ground for Dipole Antennas
}

\author{
L. E. Vogler and J. L. Noble \\ Central Radio Propagation Laboratory \\ National Bureau of Standards \\ Boulder, Colorado
}

Most of the work in this Monograph was sponsored by the Jet Propulsion Laboratory, Pasadena, Calif., as part of the Lunar Point-to-Point Communication Study

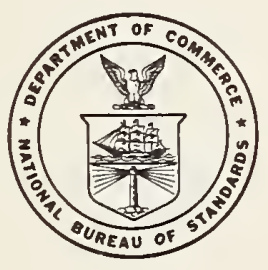

National Bureau of Standards Monograph 72 Issued January 31, 1964 
Library of Congress Catalog Card Number: 63-62354 
Contents

1. Introduction.

2. Input impedance $\ldots \ldots$

3. Limiting expressions .

4. References

5. Appendix

6. Graphs of normalized input impedance change $\Delta \mathrm{Z} / \mathrm{R}_{\mathrm{t} \ldots \ldots} \ldots \ldots \ldots$ 


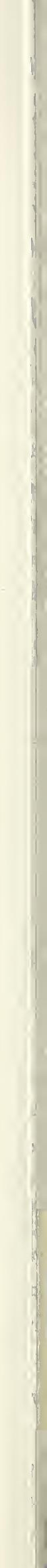


L. E. Vogler and J. L. Noble

Graphs of the change in input impedance of electrically short dipole antennas in the presence of an isotropic and homogeneous ground are presented, considering four types of antennas: horizontal and vertical, electric and magnetic dipoles. Curves of the change in both the input resistance and reactance are shown for a wide range of values of the frequency, antenna height above the ground, and electromagnetic ground constants.

\section{INTRODUCTION}

A vast amount of literature exists on the subject of dipole antennas, a considerable portion of which is devoted to impedance properties. Tabulations and curves of input impedance are available for restricted ranges of the parameters involved and for particular types of dipoles; however, no comprehensive numerical work on the subject is known to the authors. It is hoped that the present paper, although not comprehensive in the final sense, may serve as a step towards providing complete numerical information on dipole impedance in the presence of conducting ground.

Impedance evaluations are importan ance [Norton, 1959; Vogler and Noble, 1963], but are also coming into use in some of the newer methods of geophysical exploration [Wait, 1951; 1959], Data from impedance measurements obtained by sending out lunar or planetary probes that relay back the appropriate information can be used to help answer questions affecting communication requirements of manned exploration projects [Vogler, 1963].

The curves in the present paper give the change in both the resistance and reactance of four types of antennas: vertical and horizontal, electric and magnetic dipoles. Emphasis has been placed on the more poorly conducting materials that are expected in lunar communication systems; however, estimates of input impedance for highly conducting grounds may also be obtained from the curves.

\section{INPUT IMPEDANCE}

It is assumed that an elementary dipole of length de is located at the origin of a cylindrical coordinate system $(\rho, \theta, z)$ at a height $h$ above an isotropic and homogeneous conducting halfspace characterized by a dielectric constant $\epsilon_{1}$ and conductivity $\sigma_{1}$. The interface between the two media is the plane $z=-h$, and for $z>-h$ the dielectric constant is assumed to be equal to the free space value $\epsilon_{0^{\circ}}$. The magnetic permeability of the whole space is taken as the free space value $\mu_{0^{\circ}}$ (MKS units are used throughout this paper.) In the case of a vertical dipole, the antenna is oriented in the $z$ direction, whereas, for a horizontal dipole, the orientation is in the $\theta=0$ direction. The elementary magnetic dipole may be considered equivalent to a small circular loop with its axis in the direction of the dipole and with an area $d A=d \ell / \beta_{0}$, where $\beta_{0}$ is the free space wave number $(=2 \pi / \lambda)$. For practical short dipoles having a linear distribution of current, d $\boldsymbol{\ell}$ should be replaced by an effective length $\ell_{\mathrm{e}}=\mathrm{d} \ell / 2$.

For a dipole antenna with the current varying as $I_{0} e^{i \omega t}, I_{0}$ a constant, expressions for the field components have been derived by various authors [Sommerfeld and Renner, 1942; Wait, 1953, 1961; King, 1956 ]. A brief discussion of the subject is also contained in the appendix to this paper. The components of interest in the present impedance considerations are given by equations (A-11) of 
the appendix, where $\vec{E}$ denotes the electric vector (in volts per meter) associated with electric

dipoles, and $\vec{B}$ denotes the magnetic vector (in webers per square meter) associated with magnetic dipoles.

Using the "emf method" [King, 1956 (p. 258); Wait, 1962], one may find the input impedance $\mathrm{Z}$ in terms of the field components at the antenna by taking the limits of (A-11) as both $\mathrm{z}$ and $\rho$ approach zero. Thus, for the electric dipole,

$$
Z=\operatorname{Lim}_{\substack{z \rightarrow 0 \\ \rho \rightarrow 0}}\left\{\frac{E d \ell}{I_{0}}\right\} \equiv z_{f}+\Delta z
$$

and for the magnetic dipole,

$$
Z=\operatorname{Lim}_{\substack{z \rightarrow 0 \\ \rho \rightarrow 0}}\left\{\frac{\omega B d A}{I_{0}}\right\} \equiv Z_{f}+\Delta Z
$$

Here, $Z_{f}$ is defined as $Z_{f} \equiv \operatorname{Lim}_{h \rightarrow \infty} Z$, and $\Delta \mathrm{Z}$ is then that portion of the impedance that is affected by the presence of the ground $(z<-h)$.

If one now substitutes the variable $x=2 \mathrm{hu}$ in $(A-12)$ of the appendix and normalizes the impedance change $\Delta \mathrm{Z}$ by dividing by the free space resistance of the antenna, $R_{f} \equiv R$ e $Z_{f}$, the following expressions for the normalized input impedance change due to the presence of the ground is obtained (VED, HED, VMD, HMD refer to the initial letters of the four types of dipoles considered):

VED: $\Delta Z / R_{f}=i\left(3 / 2 \alpha^{3}\right)\left[I_{1}\left(N^{2}\right)+I_{2}\left(N^{2}\right)\right], \quad R_{f}=20 \beta_{o}^{2}(d \ell)^{2}$,

HED: $\Delta Z / R_{f}=i\left(3 / 4 \alpha^{3}\right)\left[I_{1}(1)+I_{2}\left(N^{2}\right)\right], \quad R_{f}=20 \beta_{o}^{2}(d l)^{2}$,

$V M D: \Delta Z / R_{f}=i\left(3 / 2 \alpha^{3}\right)\left[I_{1}(1)+I_{2}(1)\right], \quad R_{f}=20 \beta_{o}^{4}(d A)^{2}$,

HMD: $\Delta \mathrm{Z} / \mathrm{R}_{\mathrm{f}}=\mathrm{i}\left(3 / 4 \alpha^{3}\right)\left[\mathrm{I}_{1}\left(\mathrm{~N}^{2}\right)+\mathrm{I}_{2}(1)\right], \mathrm{R}_{\mathrm{f}}=20 \beta_{\mathrm{o}}^{4}(\mathrm{dA})^{2}$,

where

$$
\begin{aligned}
& I_{1}(\delta)=\alpha^{2} \int_{i \alpha}^{\infty}\left\{\frac{\delta x-\sqrt{x^{2}-\alpha^{2}\left(N^{2}-1\right)}}{\delta x+\sqrt{x^{2}-\alpha^{2}\left(N^{2}-1\right)}}\right\} \quad e^{-x} d x, \\
& I_{2}(\delta)=\int_{i \alpha}^{\infty} x^{2}\left\{\frac{\delta x-\sqrt{x^{2}-\alpha^{2}\left(N^{2}-1\right)}}{\delta x+\sqrt{x^{2}-\alpha^{2}\left(N^{2}-1\right)}}\right\} \quad e^{-x} d x,
\end{aligned}
$$




$$
\alpha=2 \mathrm{~h} \beta_{0}=2 \mathrm{~h}(2 \pi / \lambda), \quad \mathrm{N}^{2}=\left(\epsilon_{1} / \epsilon_{0}\right)-\mathrm{i}\left(\sigma_{1} / \omega \epsilon_{0}\right) .
$$

The variable $x$ in (2.3) assumes purely imaginary values from the lower limit to zero and from there ranges over real values to the upper limit. The sign of the square root is chosen such that the real part is greater than zero.

The expressions in (2.2) were programmed for an electronic computer, Gaussian quadrature methods being used for the integrals of (2.3). Graphs of the normalized input impedance change $\Delta \mathrm{Z} / \mathrm{R}_{\mathrm{f}}$ for the four different antennas are shown in the figures with the parameters $|\mathrm{N}|, \phi / 2$, and $\alpha$ defined by:

$$
|N|=\left[\epsilon_{r}^{2}+s^{2}\right]^{1 / 4}, \phi / 2=\frac{1}{2} \tan ^{-1}\left(s / \epsilon_{r}\right), \quad \alpha=(2 h)(2 \pi / \lambda)
$$

where

$$
\epsilon_{r}=\epsilon_{1} / \epsilon_{0}, s=\sigma_{1} / \omega \epsilon_{0}=60 \lambda \sigma(\operatorname{mhos} / \mathrm{m})
$$

and $\sigma(\mathrm{mhos} / \mathrm{m})$ is the conductivity of the ground; $\lambda$ denotes the free space wavelength, and $h$ denotes the antenna height, both measured in meters.

\section{LIMITING EXPRESSIONS}

From a study of the curves, it is apparent that there can be a large variation in impedance as the antenna height is varied. In fact as the antenna approaches the ground, the impedance, and especially the reactance, become very large. This latter effect, in the limiting case of $h \simeq 0$, is a mathematical result rather than a physical one, due to the infinitesimal dimensions assumed for the elementary dipole.

An attempt was made in the curves to show impedance detail for both large heights and small heights (large $\alpha$ and small $\alpha$ ). However, for values not obtainable from the graphs, the following expressions derived from an integration by parts of the integrals involved may be used at the two extremes.

For $\alpha \mathrm{N}>>1$ :

VED: $\Delta Z / R_{f} \sim \frac{3}{\alpha^{3}}\left\{\frac{N-1}{N+1}\right\}\left[(1+4 / N)+i\left\{\alpha+\frac{6}{\alpha N}\left(1-\frac{2 N-3}{N^{2}}\right)\right\}\right] i e^{-i \alpha}$,

HED: $\Delta \mathrm{Z} / \mathrm{R}_{\mathrm{f}} \sim \frac{3}{2 \alpha^{3}}\left\{\frac{\mathrm{N}-1}{\mathrm{~N}+1}\right\}\left[\left(1-\alpha^{2}+2 / N\right)+\mathrm{i}\left\{\alpha+\frac{6}{\alpha \mathrm{N}}\left(1-\frac{2 \mathrm{~N}-3}{\mathrm{~N}^{2}}\right)\right\}\right] \mathrm{i} \mathrm{e}^{-\mathrm{i} \alpha}$,

$V M D: \Delta Z / R_{f} \sim-\frac{3}{\alpha}\left\{\frac{N-1}{N+1}\right\}\left[(1-4 / N)+i\left\{\alpha+\frac{6}{\alpha N}\left(1-\frac{2 N+1}{N^{2}}\right)\right\}\right] i e^{-i \alpha}$,

$\mathrm{HMD}: \Delta \mathrm{Z} / \mathrm{R}_{\mathrm{f}} \sim-\frac{3}{2 \alpha^{3}}\left\{\frac{\mathrm{N}-1}{\mathrm{~N}+1}\right\}\left[\left(1-\alpha^{2}-6 / \mathrm{N}\right)+i\left\{\alpha+\frac{6}{\alpha \mathrm{N}}\left(1-\frac{2 \mathrm{~N}+1}{\mathrm{~N}^{2}}\right)\right\}\right] \mathrm{i} \mathrm{e}^{-\mathrm{i} \alpha}$. 
For $\alpha \mathrm{N}<<1$ :

$\mathrm{VED}: \Delta \mathrm{Z} / \mathrm{R}_{f} \simeq \frac{3(\mathrm{~N}+1)}{4}\left[\mathrm{~F}_{1}(\mathrm{D})+\left(\frac{\mathrm{N}+1}{2}\right)^{2} \mathrm{~F}_{2}(\mathrm{D})\right]+i\left\{\frac{3(1+\mathrm{A}) \mathrm{D}}{\alpha^{3}}\right\} \mathrm{e}^{-\mathrm{A}}$,

HED: $\quad \Delta Z / R_{f} \simeq \frac{3(N+1)}{8}\left[F_{1}(0)+\left(\frac{N+1}{2}\right)^{2} F_{2}(D)\right]+i\left\{\frac{3(1+A) D}{2 \alpha^{3}}\right\} e^{-A}$,

VMD: $\Delta Z / R_{f} \simeq \frac{3(N+1)}{4}\left[F_{1}(0)+\left(\frac{N+1}{2}\right)^{2} F_{2}(0)\right]+i\left\{\frac{3\left(N^{2}+1\right) D}{8 \alpha}\right\} e^{-A}$,

$H M D: \quad \Delta Z / R_{f} \simeq \frac{3(N+1)}{8}\left[F_{1}(D)+\left(\frac{N+1}{2}\right)^{2} F_{2}(0)\right]+i\left\{\frac{3\left(N^{2}+5\right) D}{16 \alpha}\right\} e^{-A}$,

where

$$
F_{1}(X)=X+\{1-X(1+X)\} d+\frac{1}{3}(1+X)\left(1-X^{2}\right) d^{2}
$$

$F_{2}(X)=-\frac{X}{3}+\{1+X(1-X)\} d+\{1-X(1+X)(2-X)\} d^{2}+\frac{1}{3}\left\{1+X(1-X)\left(2-X^{2}\right)\right\} d^{3}-\frac{1}{5}(1-X)\left(1-X^{2}\right)^{2} d^{4}$,

$$
d \equiv \frac{N-1}{N+1}, \quad D \equiv \frac{N^{2}-1}{N^{2}+1}, \quad A \equiv \alpha \sqrt{N^{2}-1}
$$

For the case of dipoles above a perfectly conducting plane $(N \rightarrow \infty)$, equations $(3.1)$ reduce to the well-known expressions:

$\mathrm{VED}: \Delta \mathrm{Z} / \mathrm{R}_{\mathrm{f}} \rightarrow\left(\frac{3}{\alpha^{3}}\right)[\{\sin \alpha-\alpha \cos \alpha\}+\mathrm{i}\{\cos \alpha+\alpha \sin \alpha\}]$,
$\mathrm{HED:} \quad \Delta \mathrm{Z} / \mathrm{R}_{\mathrm{f}} \rightarrow\left(\frac{3}{2 \alpha^{3}}\right)\left[\left\{\left(1-\alpha^{2}\right) \sin \alpha-\alpha \cos \alpha\right\}+i\left\{\left(1-\alpha^{2}\right) \cos \alpha+\alpha \sin \alpha\right\}\right]$,

$\mathrm{VMD}: \Delta \mathrm{Z} / \mathrm{R}_{\mathrm{f}} \rightarrow-\left(\frac{3}{\alpha}\right)[\{\sin \alpha-\alpha \cos \alpha\}+\mathrm{i}\{\cos \alpha+\alpha \sin \alpha\}]$,

$\mathrm{HMD}: \Delta \mathrm{Z} / \mathrm{R}_{\mathrm{f}} \rightarrow-\left(\frac{3}{2 \alpha^{3}}\right)\left[\left\{\left(1-\alpha^{2}\right) \sin \alpha-\alpha \cos \alpha\right\}+i\left\{\left(1-\alpha^{2}\right) \cos \alpha+\alpha \sin \alpha\right\}\right]$. 


\section{REFERENCES}

King, R. W. P. (1956). The theory of linear antennas, (Harvard University Press, Cambridge, Mass.).

Norton, K. A. (July-Aug. 195\%). System loss in radio wave propagation, J. Res. NBS 63D (Radio Prop.), No. 1, 53-73.

Sommerfeld, A., and F. Renner (1942). Strahlungsenergie und Erdabsorption bei Dipolantennen, Ann. Phys. $\underline{41}$, No. $1,1-36$.

Vogler, L. E. (Jan.-Feb. 1963). Point-to-point communication on the moon, J. Res. NBS 67D (Radio Prop.), No. 1, 5-21.

Vogler, L. E., and J. L. Noble (1963). Curves of ground proximity loss for dipole antennas, NBS Tech. Note 175 .

Wait, J. R. (Nov. 1951). The magnetic dipole over the horizontally stratified earth, Can. J. Phys. 29, $577-592$.

Wait, J. R. (May, 1953). Radiation resistance of a small circular loop in the presence of a conducting ground, J. Appl. Phys. 24, No. 5, 646-649.

Wait, J. R. (1959). Overvoltage research and geophysical applications, (Pergamon Press, New York, N. Y.).

Wait, J. R. (July, 1961). The electromagnetic fields of a horizontal dipole in the presence of a conducting half-space, Can. J. Phys. 39, 1017-1028.

Wait, J. R. (Sept.-Oct. 1962). Possible influence of the ionosphere on the impedance 'of a groundbased antenna, J. Res. NBS 66D (Radio Prop.), No. 5, 563-569.

\section{APPENDIX}

The electromagnetic field of an elementary dipole above a conducting plane (see section 2 for orientation and location) may be obtained from the electric and magnetic Hertzian potentials, $\vec{\Pi}$ e and $\vec{r}_{\mathrm{m}}$, the components of which, if the vectors are referred to a cartesian coordinate system ( $\mathrm{x}, \mathrm{y}$, 2), satisfy the scalar wave equation $\left(\nabla^{2}+\beta^{2}\right) \Pi=0$. Using the cylindrical coordinate form of the wave equation, particular solutions are found by the method of separation of variables, resulting in expressions for the $\Pi$ components involving combinations of the eigenfunction

$$
\cos n \theta J_{n}(\lambda \rho) C(\lambda, \beta) \exp \left\{ \pm \sqrt{\lambda^{2}-\beta^{2}} z\right\},
$$

where $\lambda$ denotes the eigenvalue (following Sommerfeld's notation), $J_{n}$ is a Bessel function of the first kind and order $n$, and the C's are functions determined from the boundary conditions. These conditions, in the present instance, require that the tangential components of the electric vector $\vec{E}$ and the magnetic vector $\vec{B}$ be continuous at the interface between the two media (air and ground). In the case of vertical dipoles, $\vec{E}$ and $\vec{B}$ may be expressed in terms of Hertzian potentials having a $z$-component only. Thus, in the upper medium,

$$
\vec{\Pi}_{\text {vert }}=\Pi_{z} \vec{z}=\left(\Pi_{z}^{d}+\Pi_{z}^{r}\right) \vec{z}
$$

where the superscripts $d$ and $r$ refer to the direct or primary stimulation and the reflected or secondary stimulation, respectively. After solving for the coefficients $C$ through the boundary 
conditions, one finds that for

VED: $\quad \Pi_{e z}^{d}=\frac{i K e}{\beta_{o}} \int_{0}^{\infty} J_{o}(\lambda \rho) e^{-z u_{o}}\left(\lambda / u_{o}\right) d \lambda$,

$$
\Pi_{e z}^{r}=\frac{i K e}{\beta_{o}} \int_{0}^{\infty} J_{o}(\lambda \rho)\left\{\frac{N^{2} u_{o}-u_{1}}{N^{2} u_{0}+u_{1}}\right\} e^{-(z+2 h) u_{0}}\left(\lambda / u_{0}\right) d \lambda,
$$

VMD: $\Pi_{m z}^{d}=\frac{i K m}{\beta_{0}} \int_{0}^{\infty} J_{o}(\lambda \rho) e^{-z u_{o}}\left(\lambda / u_{o}\right) d \lambda$,

$$
\Pi_{m z}^{r}=\frac{i K m}{\beta_{0}} \int_{0}^{\infty} J_{0}(\lambda \rho)\left\{\frac{u_{0}-u_{1}}{u_{0}+u_{1}}\right\} e^{-(z+2 h) u_{0}}\left(\lambda / u_{0}\right) d \lambda,
$$

where

$$
u_{0}=\sqrt{\lambda^{2}-\beta_{0}^{2}}, \quad u_{1}=\sqrt{\lambda^{2}-\beta_{1}^{2}}, N^{2}=\left(\epsilon_{1} / \epsilon_{0}\right)-i\left(\sigma_{1} / \omega \epsilon_{0}\right) .
$$

$\beta_{0}$ and $\beta_{1}$ are propagation constants of the upper and lower media, respectively, and the K's are amplitude factors given by

$$
K_{e}=\frac{\beta_{0} I_{o}(d l)}{4 \pi \omega \epsilon}, K_{m}=\frac{\beta_{0} \mu_{0} I_{0}(d A)}{4 \pi} .
$$

For horizontal dipoles, the Hertzian potentials require both an $\mathrm{x}$ - and a $\mathrm{z}$-component. Thus, corresponding to $(\mathrm{A}-2)$,

$$
\vec{\Pi}_{\text {hor }}=\Pi_{x} \vec{x}+\Pi_{z} \vec{z}=\left(\Pi_{x}^{d}+\Pi_{x}^{r}\right) \vec{x}+\Pi_{z} \vec{z}
$$

After solving for the C's through the boundary conditions, one obtains:

$$
\text { HED: } \left.\begin{array}{rl}
\Pi_{e x}^{d} & =\frac{i K e}{\beta_{0}} \int_{0}^{\infty} J_{0}(\lambda \rho) e^{-z u_{o}}\left(\lambda / u_{o}\right) d \lambda, \\
\Pi_{e x}^{r} & =\frac{i K_{e}}{\beta_{0}} \int_{0}^{\infty} J_{0}(\lambda \rho)\left\{\frac{u_{0}-u_{1}}{u_{0}+u_{1}}\right\} e^{-(z+2 h) u_{o}}\left(\lambda / u_{0}\right) d \lambda, \\
\Pi_{e z} & =-\frac{i K_{e} \cos \theta}{\beta_{0}} \int_{0}^{\infty} J_{1}(\lambda \rho)\left\{\frac{2\left(u_{0}-u_{1}\right)}{N^{2} u_{0}+u_{1}}\right\} e^{-(z+2 h) u_{o}}\left(\lambda^{2} / \beta_{0}^{2}\right) d \lambda,
\end{array}\right\}
$$


HMD: $\quad \Pi_{m x}^{d}=\frac{i K m}{\beta_{0}} \int_{0}^{\infty} J_{0}(\lambda \rho) e^{-z u_{o}}\left(\lambda / u_{0}\right) d \lambda$,

$$
\begin{aligned}
& \Pi_{m x}^{r}=\frac{i K m}{\beta_{0}} \int_{0}^{\infty} J_{0}(\lambda \rho)\left\{\frac{N^{2} u_{0}-u_{1}}{N^{2} u_{0}+u_{1}}\right\} e^{-(z+2 h) u_{o}}\left(\lambda / u_{0}\right) d \lambda, \\
& \Pi_{m z}=-\frac{i K_{m} \cos \theta}{\beta_{0}} \int_{0}^{\infty} J_{1}(\lambda \rho)\left\{\frac{2\left(u_{0}-u_{1}\right)}{N^{2} u_{0}+u_{1}}\right\} e^{-(z+2 h) u_{0}}\left(\lambda^{2} / \beta_{0}^{2}\right) d \lambda,
\end{aligned}
$$

where $u_{0}, u_{1}, N^{2}, K_{e}$, and $K_{m}$ are defined in $(A-5)$ and $(A-6)$.

With the Hertz vector $\vec{\Pi}$ determined, the electromagnetic field in the upper medium is derived through the following relationships:

$$
\begin{array}{ll}
\vec{E}=\operatorname{grad} \operatorname{div} \vec{\Pi}_{\mathrm{e}}+\beta_{\mathrm{o}}^{2} \vec{\Pi}_{\mathrm{e}}, \quad \text { (electric dipoles) } \\
\vec{B}=\operatorname{grad} \operatorname{div} \vec{\Pi}_{\mathrm{m}}+\beta_{\mathrm{o}}^{2} \vec{\Pi}_{\mathrm{m}} . & \text { (magnetic dipoles) }
\end{array}
$$

The components (in cylindrical coordinates) of interest in this paper are found to be

VED: $E_{z}(\rho, z)=\left(\partial^{2} / \partial z^{2}+\beta_{o}^{2}\right) \Pi_{e z}=\left(\partial^{2} / \partial z^{2}+\beta_{o}^{2}\right)\left(\Pi_{e z}^{d}+\Pi_{e z}^{r}\right)$

$$
=\frac{i K_{e}}{\beta_{0}} \int_{0}^{\infty} J_{0}(\lambda \rho)\left[e^{-z u_{0}} \cdot+\left\{\frac{N^{2} u_{0}-u_{1}}{N^{2} u_{0}+u_{1}}\right\} e^{-(z+2 h) u_{0}}\right]\left(\lambda^{3} / u_{0}\right) d \lambda,
$$

HED: $E_{\rho}(\rho, z)=(\partial / \partial \rho) \operatorname{div} \vec{\Pi}_{e}+\beta_{0}^{2} \cos \theta \Pi_{\text {ex }}$

$$
\begin{aligned}
& =\frac{i K_{e} \cos \theta}{\beta_{0}} \int_{0}^{\infty}\left[\left(\beta_{0}^{2} J_{0}(\lambda \rho)-\lambda^{2}\left\{J_{0}(\lambda \rho)-\frac{J_{1}(\lambda \rho)}{\lambda \rho}\right\}\right) e^{-z u_{0}}\right. \\
& +\left(\beta_{0}^{2} J_{0}(\lambda \rho)-\lambda^{2}\left\{J_{0}(\lambda \rho)-\frac{J_{1}(\lambda \rho)}{\lambda \rho}\right\}\right)\left\{\frac{u_{0}-u_{1}}{u_{0}+u_{1}}\right\} e^{-(z+2 h) u_{0}} \\
& \left.+\left(J_{0}(\lambda \rho)-\frac{J_{1}(\lambda \rho)}{\lambda \rho}\right)\left\{\frac{2 \lambda^{2} u_{0}^{2}\left(u_{0}-u_{1}\right)}{\beta_{0}^{2}\left(N^{2} u_{0}+u_{1}\right)}\right\} e^{-(z+2 h) u_{0}}\right]\left(\lambda / u_{0}\right) d \lambda,
\end{aligned}
$$

VMD: $\quad B_{z}(\rho, z)=\left(\partial^{2} / \partial z^{2}+\beta_{0}^{2}\right) \Pi_{m z}=\left(\partial^{2} / \partial z^{2}+\beta_{0}^{2}\right)\left(\Pi_{m z}^{d}+\Pi_{m z}^{r}\right)$

$$
=\frac{i K m}{\beta_{0}} \int_{0}^{\infty} J_{0}(\lambda \rho)\left[e^{-z u_{0}}+\left\{\frac{u_{0}-u_{1}}{u_{0}+u_{1}}\right\} e^{-(z+2 h) u_{0}}\right]\left(\lambda^{\left.3 / u_{0}\right) d \lambda,}\right.
$$


HMD: $\quad B_{\rho}(\rho, z)=(\partial / \partial \rho) \operatorname{div} \vec{\Pi}_{m}+\beta_{0}^{2} \cos \theta \Pi_{m x}$

$$
\begin{aligned}
& =\frac{i K_{m} \cos \theta}{\beta_{0}} \int_{0}^{\infty}\left[\left(\beta_{0}^{2} J_{0}(\lambda \rho)-\lambda^{2}\left\{J_{0}(\lambda \rho)-\frac{J_{1}(\lambda \rho)}{\lambda \rho}\right\}\right) e^{-z u_{0}}\right. \\
& +\left(\beta_{0}^{2} J_{0}(\lambda \rho)-\lambda^{2}\left\{J_{0}(\lambda \rho)-\frac{J_{1}(\lambda \rho)}{\lambda \rho}\right\}\right)\left\{\frac{N^{2} u_{0}-u_{1}}{N^{2} u_{0}+u_{1}}\right\} e^{-(z+2 h) u_{0}} \\
& \left.+\left(J_{0}(\lambda \rho)-\frac{J_{1}(\lambda \rho)}{\lambda \rho}\right)\left\{\frac{2 \lambda^{2} u_{0}^{2}\left(u_{0}-u_{1}\right)}{\beta_{0}^{2}\left(N^{2} u_{0}+u_{1}\right)}\right\} e^{-(z+2 h) u_{0}}\right]\left(\lambda / u_{0}\right) d \lambda .
\end{aligned}
$$

To calculate the dipole input impedance using the emf method [King, 1956 (p. 258); Wait, 1962 ] requires a knowledge of the axial field at the antenna. This may be obtained by taking the limits of (A-11) as $\rho$ and $z$ approach zero (and with $\theta=0$ in the case of horizontal dipoles). The impedance $\mathrm{Z}$ is then given by

$$
\begin{aligned}
& \text { VED: } Z=\operatorname{Lim}_{\substack{\rho \rightarrow 0 \\
z \rightarrow 0}}\left\{E_{z}(\rho, z) d \ell / I_{0}\right\} \\
& =\frac{i K_{e} d l}{\beta_{0} I_{0}} \int_{0}^{\infty}\left[1+\left\{\frac{N^{2} u_{0}-u_{1}}{N^{2} u_{0}+u_{1}}\right\} e^{-2 h u_{0}}\right]\left(\lambda^{3} / u_{0}\right) d \lambda, \\
& \text { HED: } Z=\operatorname{Lim}_{\substack{\rho \rightarrow 0 \\
z \rightarrow 0}}\left\{E_{\rho}(\rho, z) d \ell / I_{0}\right\} \\
& =\frac{i K_{e} d \ell}{\beta_{0} I_{0}} \int_{0}^{\infty}\left[\left(\beta_{0}^{2}-\lambda^{2} / 2\right)\left(1+\left\{\frac{u_{0}-u_{1}}{u_{0}+u_{1}}\right\} e^{-2 h_{0}}\right)\right. \\
& \left.+\left\{\frac{\lambda^{2} u_{0}^{2}\left(u_{0}-u_{1}\right)}{\beta_{0}^{2}\left(N^{2} u_{0}+u_{1}\right)}\right\} e^{-2 h u_{0}}\right]\left(\lambda / u_{0}\right) d \lambda \\
& \text { VMD: } Z=\operatorname{Lim}_{\substack{\rho \rightarrow 0 \\
z \rightarrow 0}}\left\{\omega B_{z}(\rho, z) d A / I_{0}\right\} \\
& =\frac{i \omega K_{m} d A}{\beta_{0} I_{0}} \int_{0}^{\infty}\left[1+\left\{\frac{u_{0}-u_{1}}{u_{0}+u_{1}}\right\} e^{-2 h u_{0}}\right]\left(\lambda^{3} / u_{0}\right) d \lambda,
\end{aligned}
$$


$\operatorname{HMD:} Z=\operatorname{Lim}_{\substack{\rho \rightarrow 0 \\ z \rightarrow 0}}\left\{\omega B_{\rho}(\rho, z) d A / I_{0}\right\}$

$$
\begin{aligned}
& =\frac{i \omega K_{m} d A}{\beta_{0} I_{0}} \int_{0}^{\infty}\left[\left(\beta_{0}^{2}-\lambda^{2} / 2\right)\left(1+\left\{\frac{N^{2} u_{0}-u_{1}}{N^{2} u_{0}+u_{1}}\right\} e^{-2 h u_{0}}\right)\right. \\
& \left.+\left\{\frac{\lambda^{2} u_{0}^{2}\left(u_{0}-u_{1}\right)}{\beta_{0}^{2}\left(N^{2} u_{0}+u_{1}\right)}\right\} e^{-2 h u_{0}}\right]\left(\lambda / u_{0}\right) d \lambda
\end{aligned}
$$

Notice that the effect of the ground is contained in terms involving the factor $\exp \left(-2 \mathrm{~h} \mathrm{u}_{\mathrm{o}}\right)$; thus, the change in impedance $\Delta \mathrm{Z}$ due to the presence of the ground may be defined as

$$
\Delta \mathrm{Z} \equiv \mathrm{Z}-\operatorname{Lim}_{\mathrm{h} \rightarrow \infty} \mathrm{Z}=\mathrm{Z}-\mathrm{Z}_{\mathrm{f}}
$$

and the free space antenna resistance $R_{f}$ is obtained from the relationship:

$$
R_{f}=\operatorname{Re}\left\{\operatorname{Lim}_{h \rightarrow \infty} z\right\} .
$$

With the use of $(A-13)$ and $(A-14)$, one can now derive the expressions for the normalized input impedance change $\Delta Z / R_{f}$ given by equations (2.2) of section 2 ; here, the change of variable

$$
x=2 h u_{0}=2 h \sqrt{\lambda^{2}-\beta_{0}^{2}}
$$

has been made and the following relationships used:

$$
\left(\lambda d \lambda / u_{0}\right)=(d x / 2 h), \quad \alpha=2 h \beta_{0}, \quad u_{1}=\sqrt{x^{2}-\alpha^{2}\left(N^{2}-1\right) / 2 h}, \quad \lambda^{2}=\left(\alpha^{2}+x^{2}\right) /(2 h)^{2}
$$


6. GRAPHS OF NORMALIZED INPUT IMPEDANCE CHANGE, $\Delta Z / R_{f}$ for

Vertical Electric Dipole (VED)

Horizontal Electric Dipole (HED)

Vertical Magnetic Dipole (VMD)

Horizontal Magnetic Dipole (HMD)

$|N|=\left[\epsilon_{r}^{2}+s^{2}\right]^{1 / 4}, \phi / 2=\left(\frac{1}{2}\right) \tan ^{-1}\left(s / \epsilon_{r}\right)$

$s=60 \lambda \sigma(\operatorname{mhos} / \mathrm{m}), \quad \alpha=(2 \mathrm{~h})(2 \pi / \lambda)$,

$\epsilon_{\mathrm{r}}$ : relative dielectric constant of ground

$\sigma(\mathrm{mhos} / \mathrm{m})$ : conductivity of ground

h: height in meters of antenna above ground

$\lambda$ : wavelength in meters 


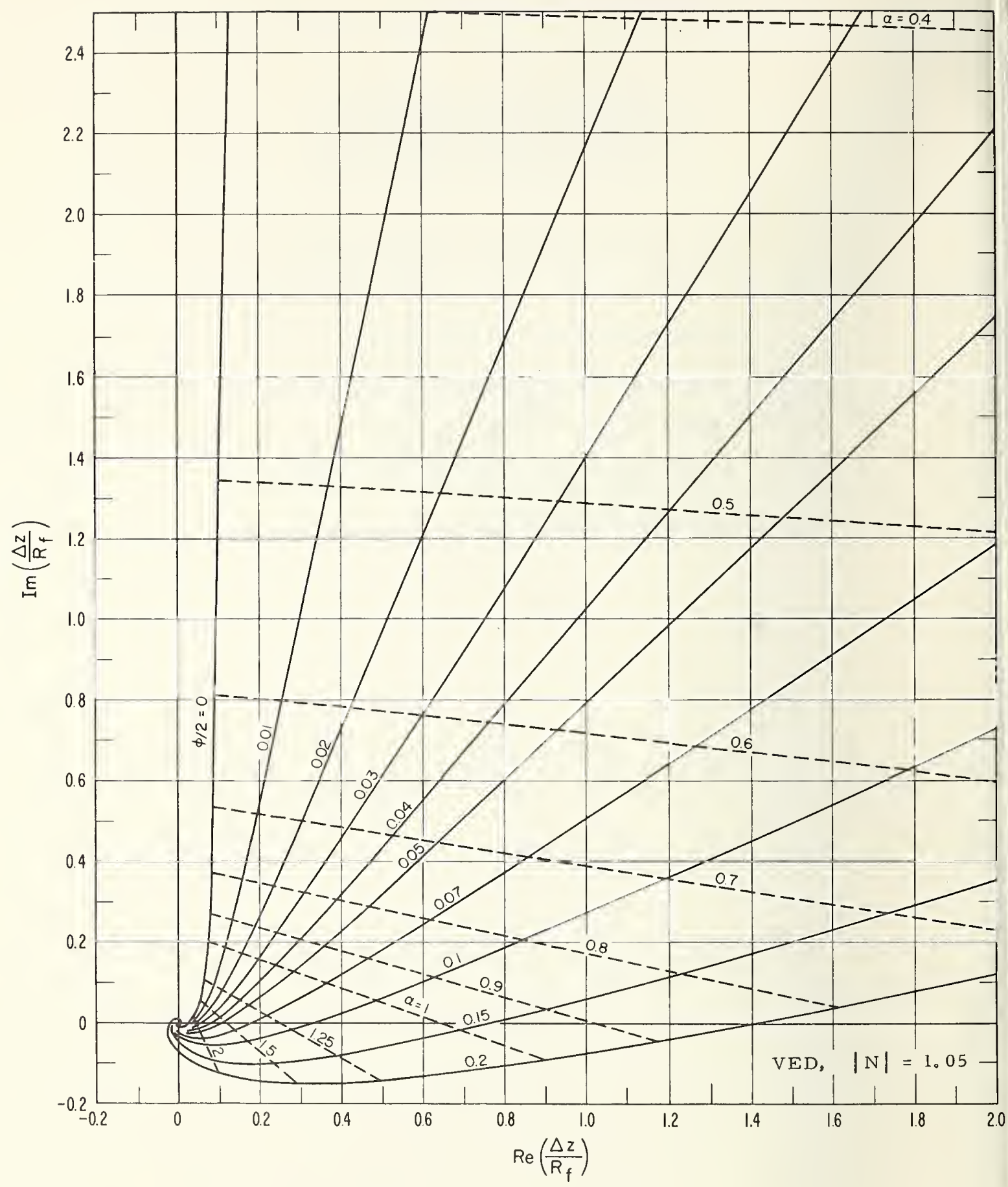

Figure 1。 


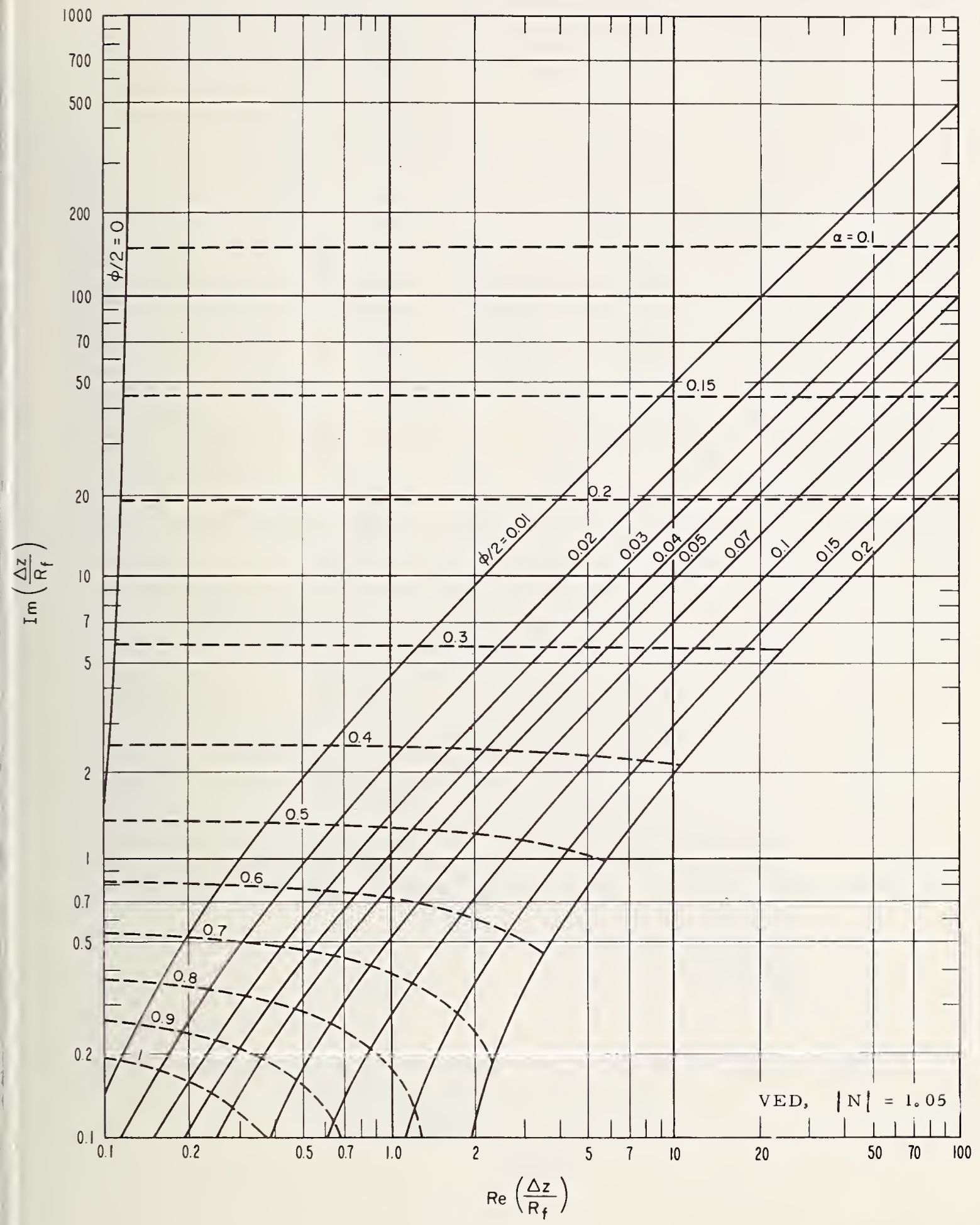

Figure 2. 


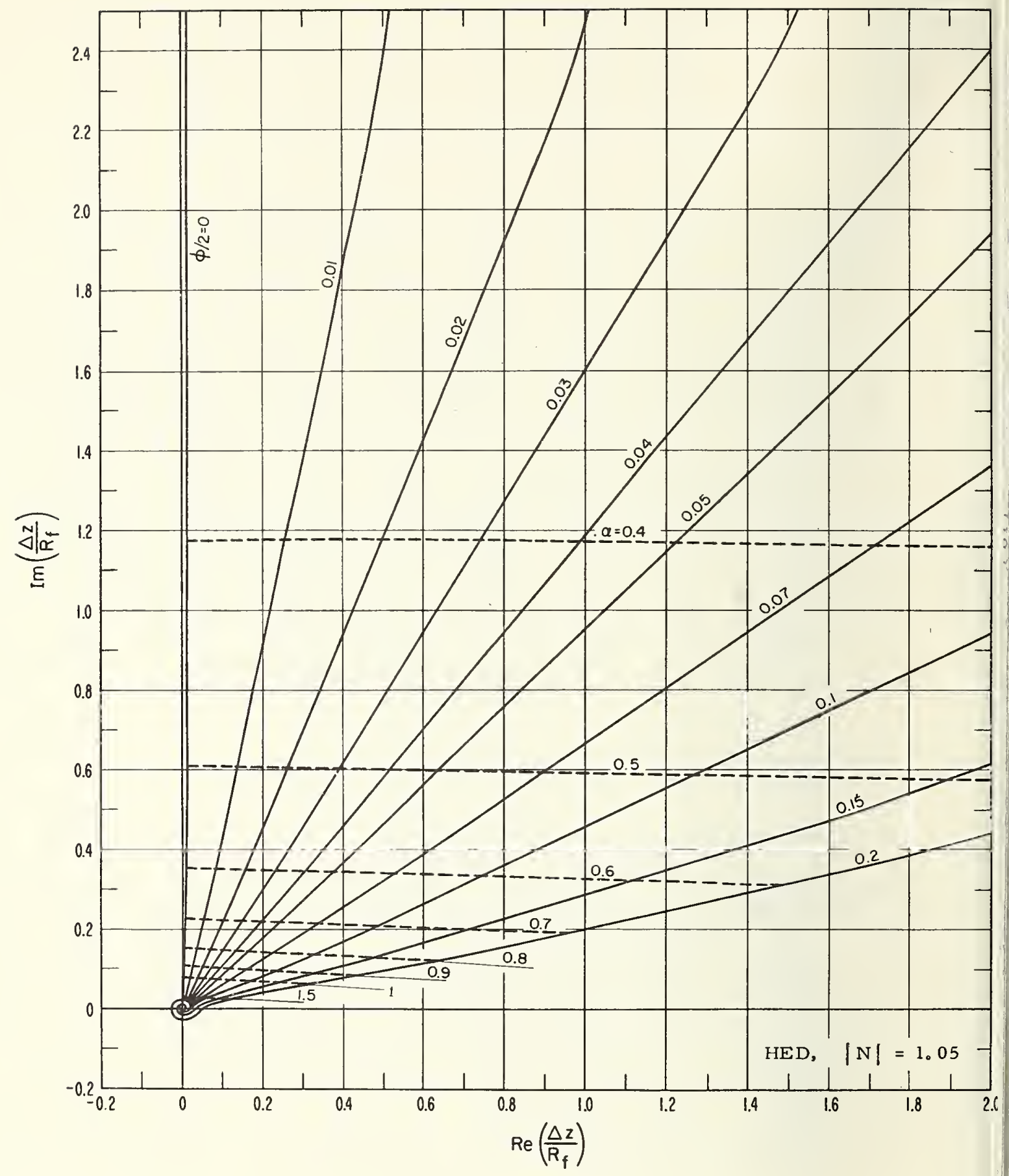

Figure 3. 


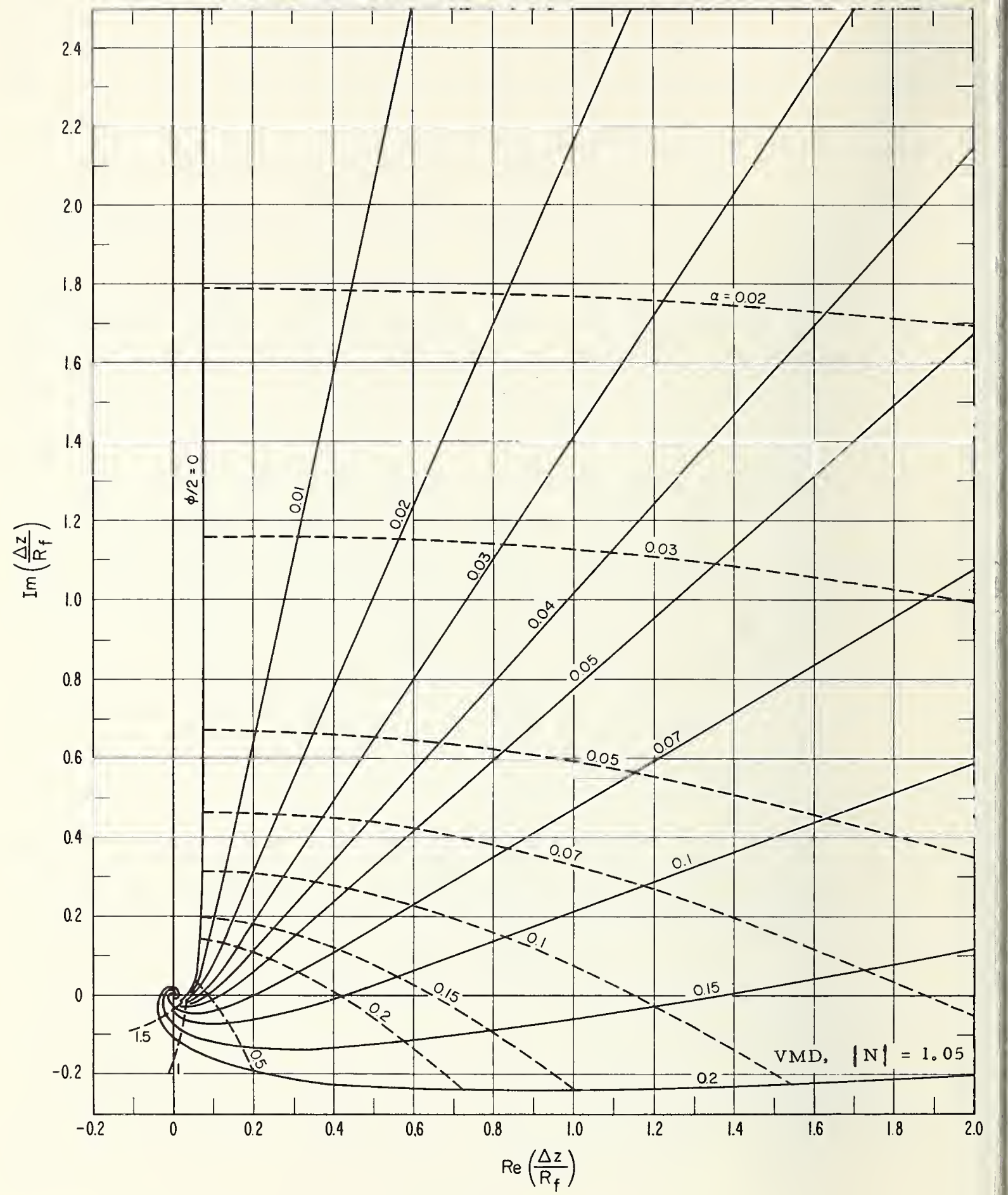

Figure 5. 


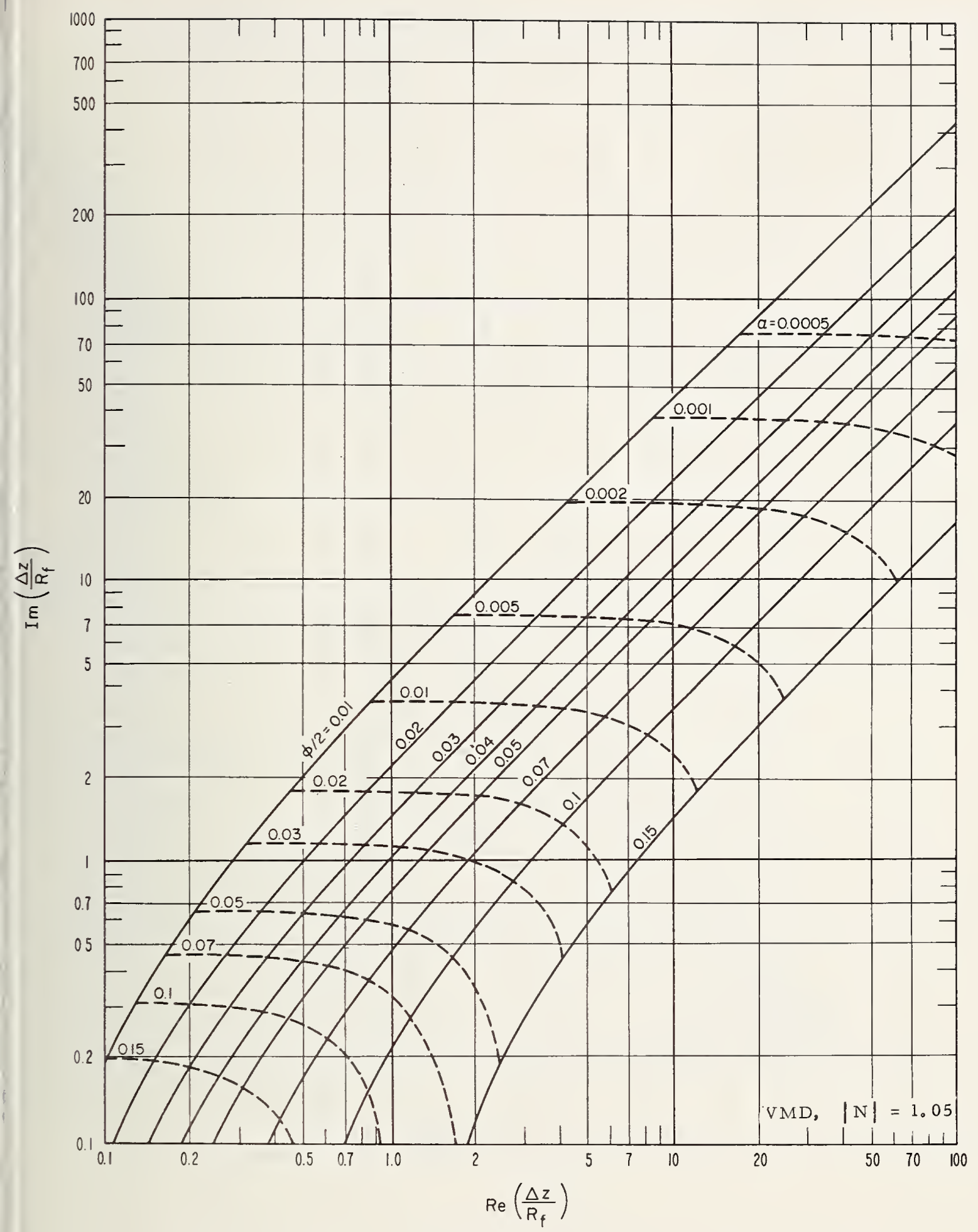

Figure 6. 


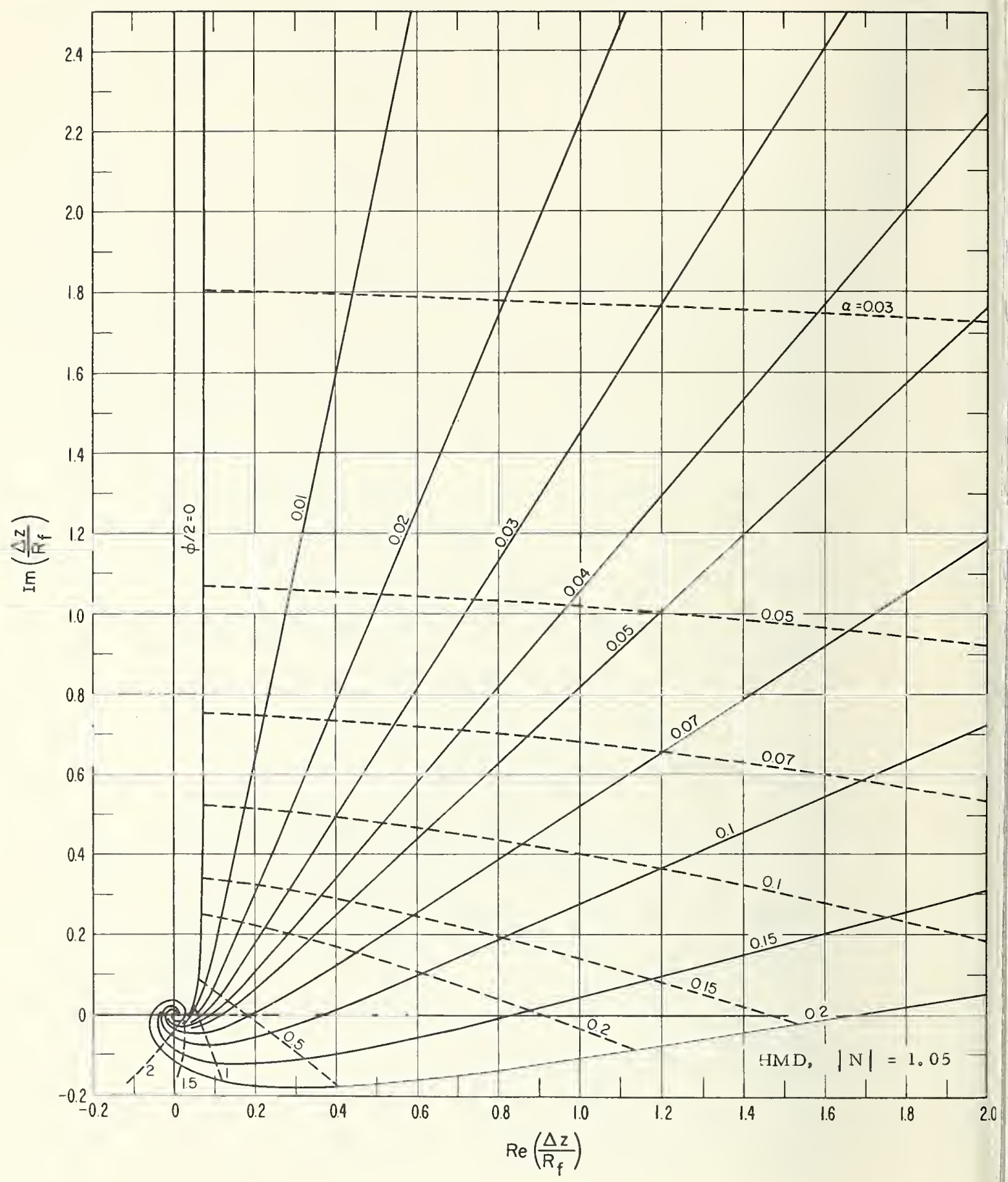

Figure 7 . 


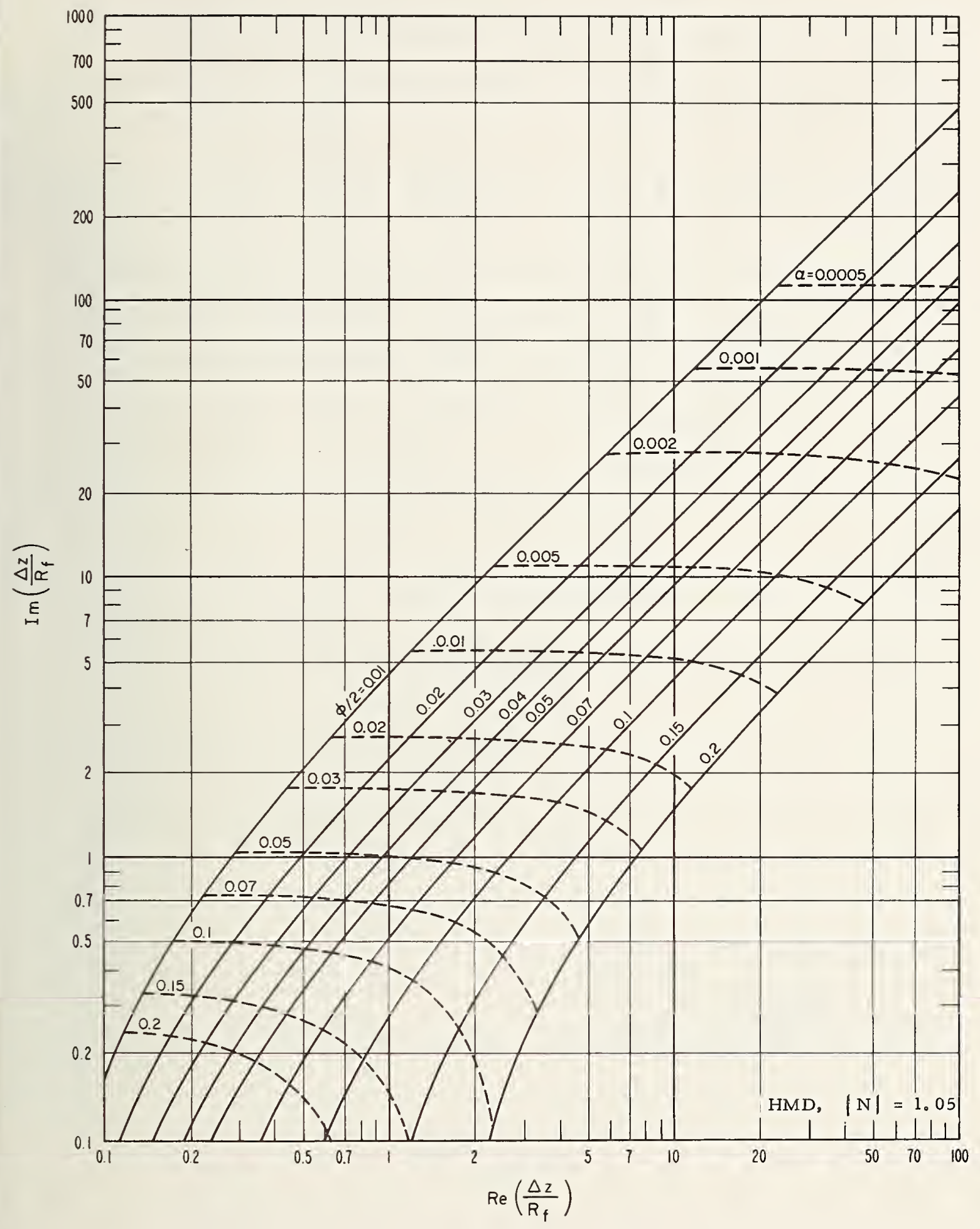

Figure 8 . 


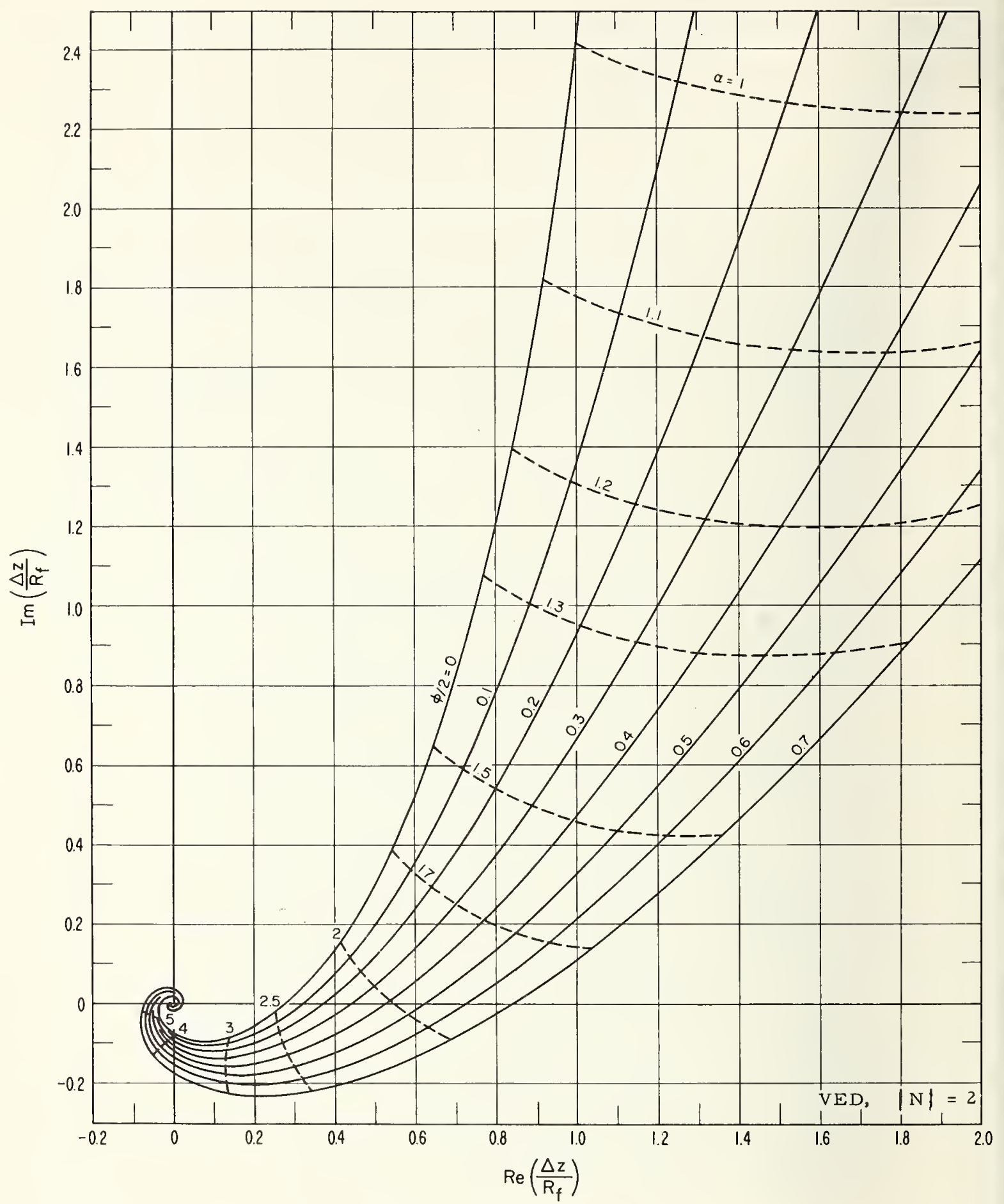

Figure 9. 


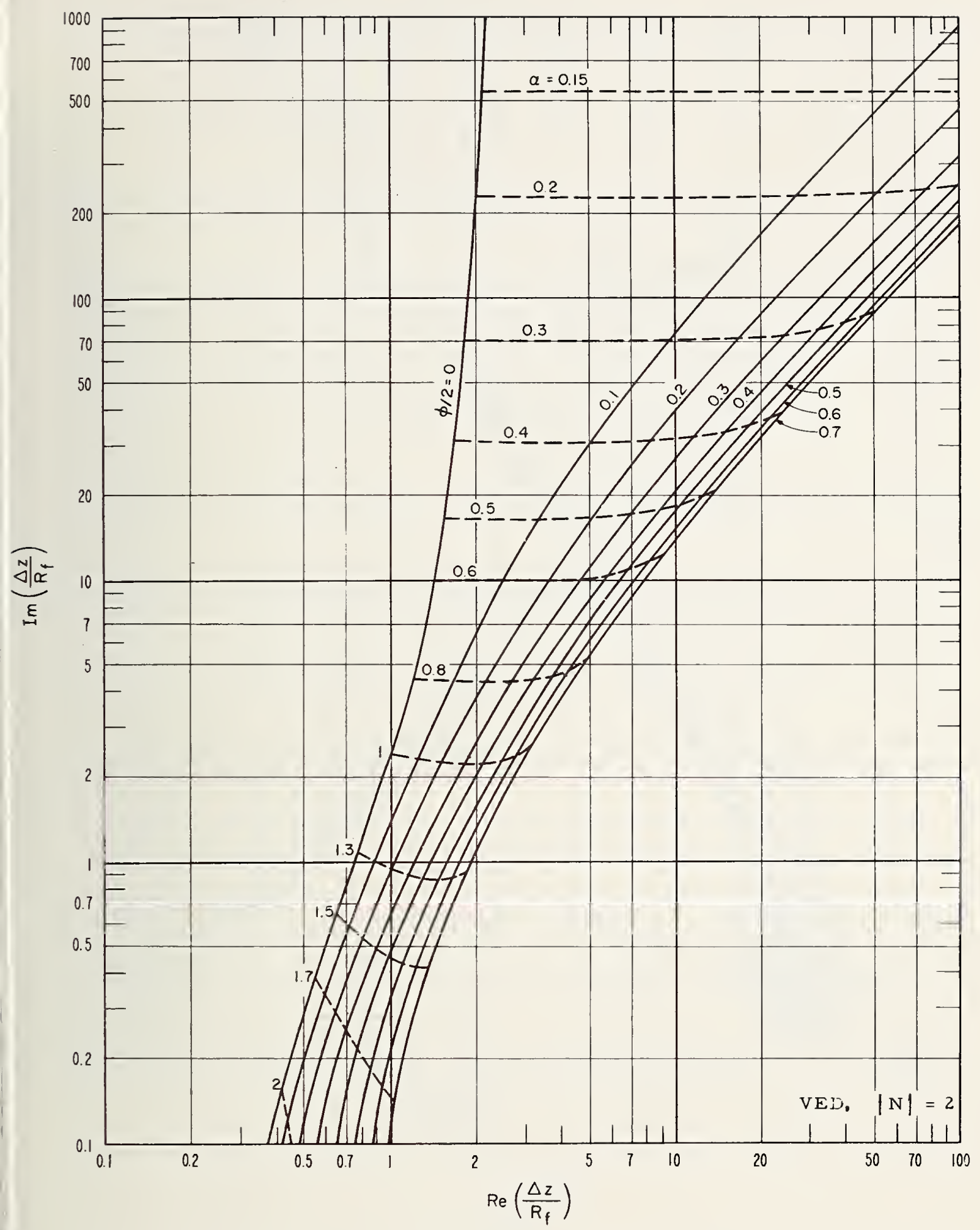

Figure 10. 


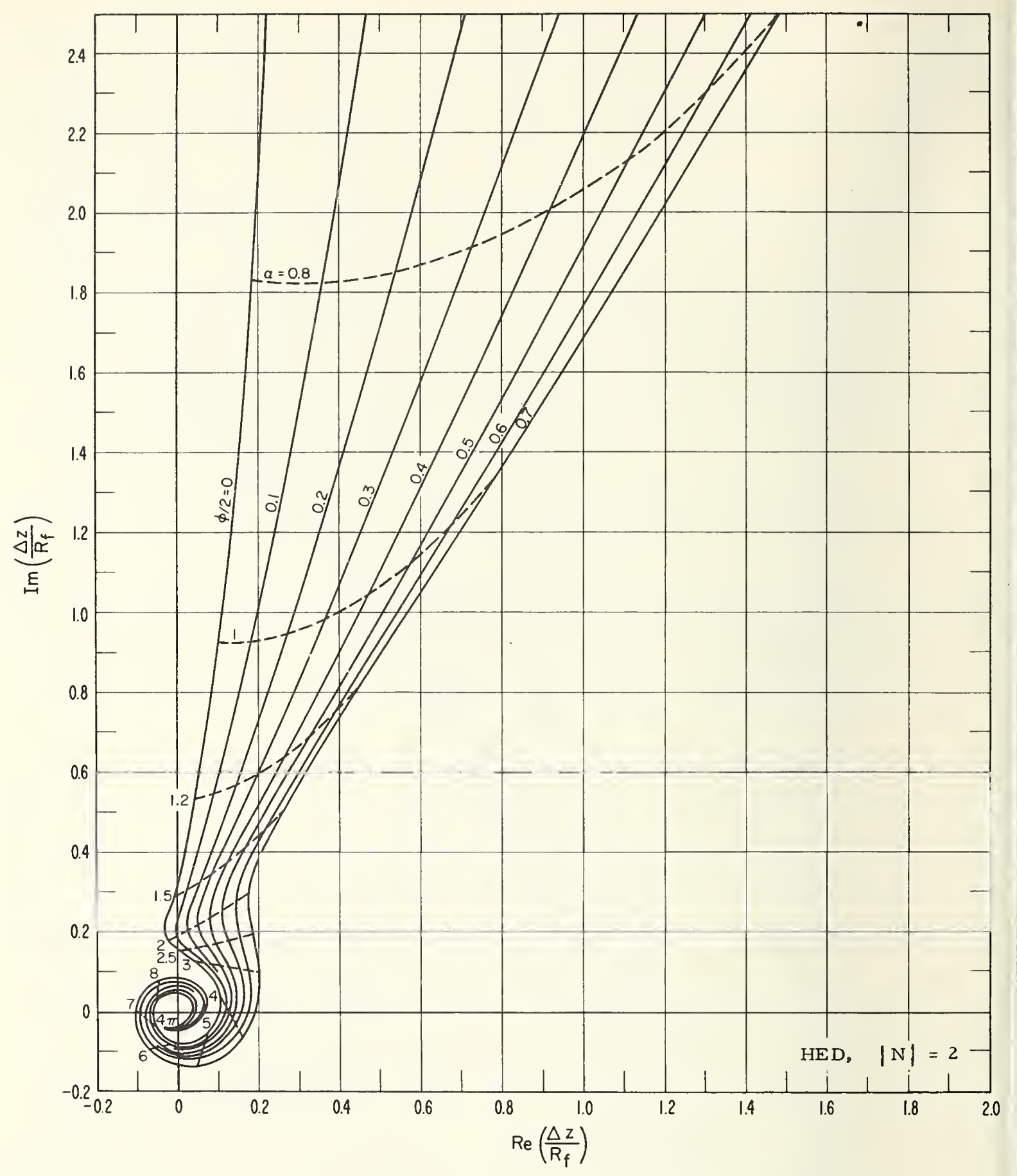

Figure 11. 


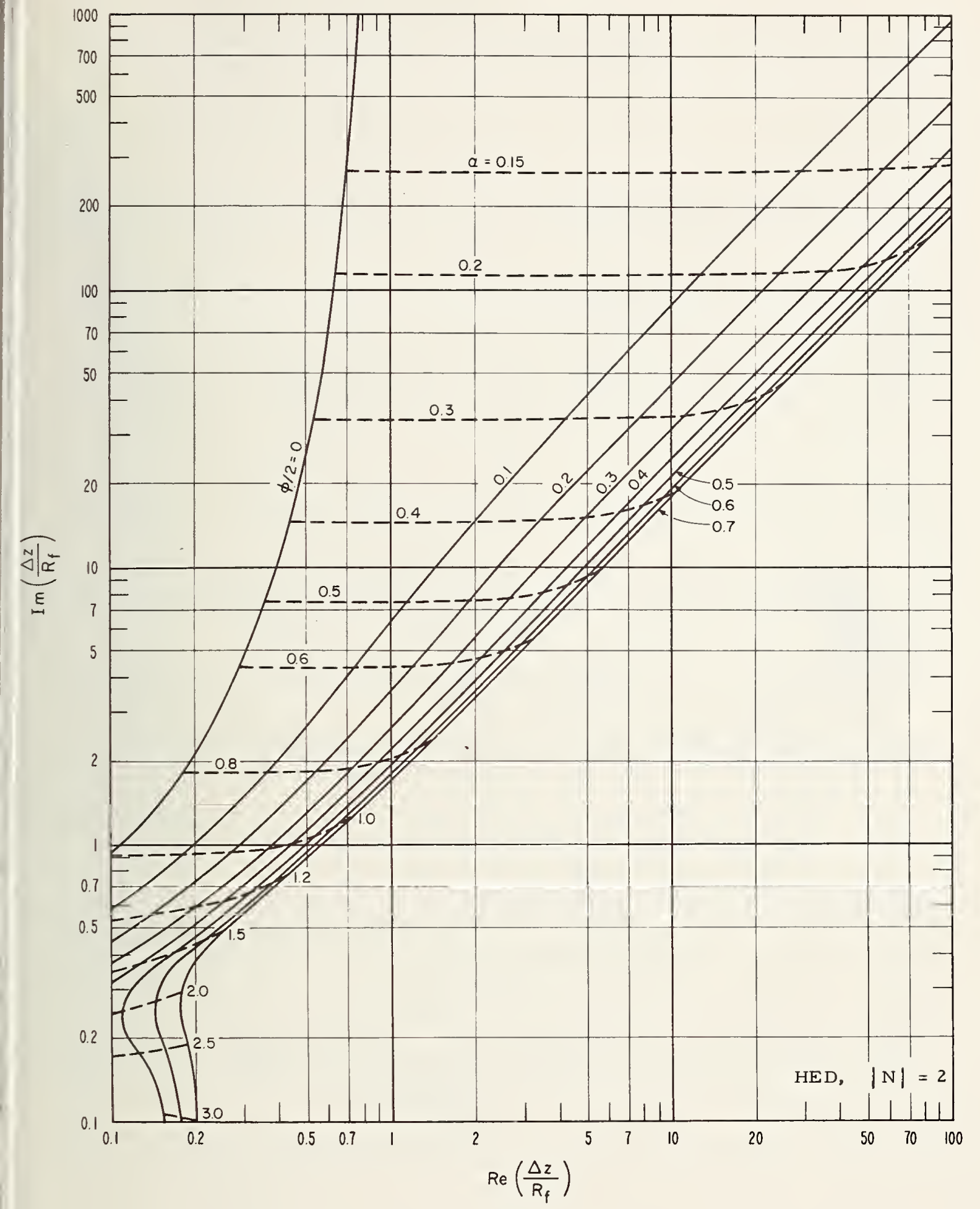

Figure 12. 


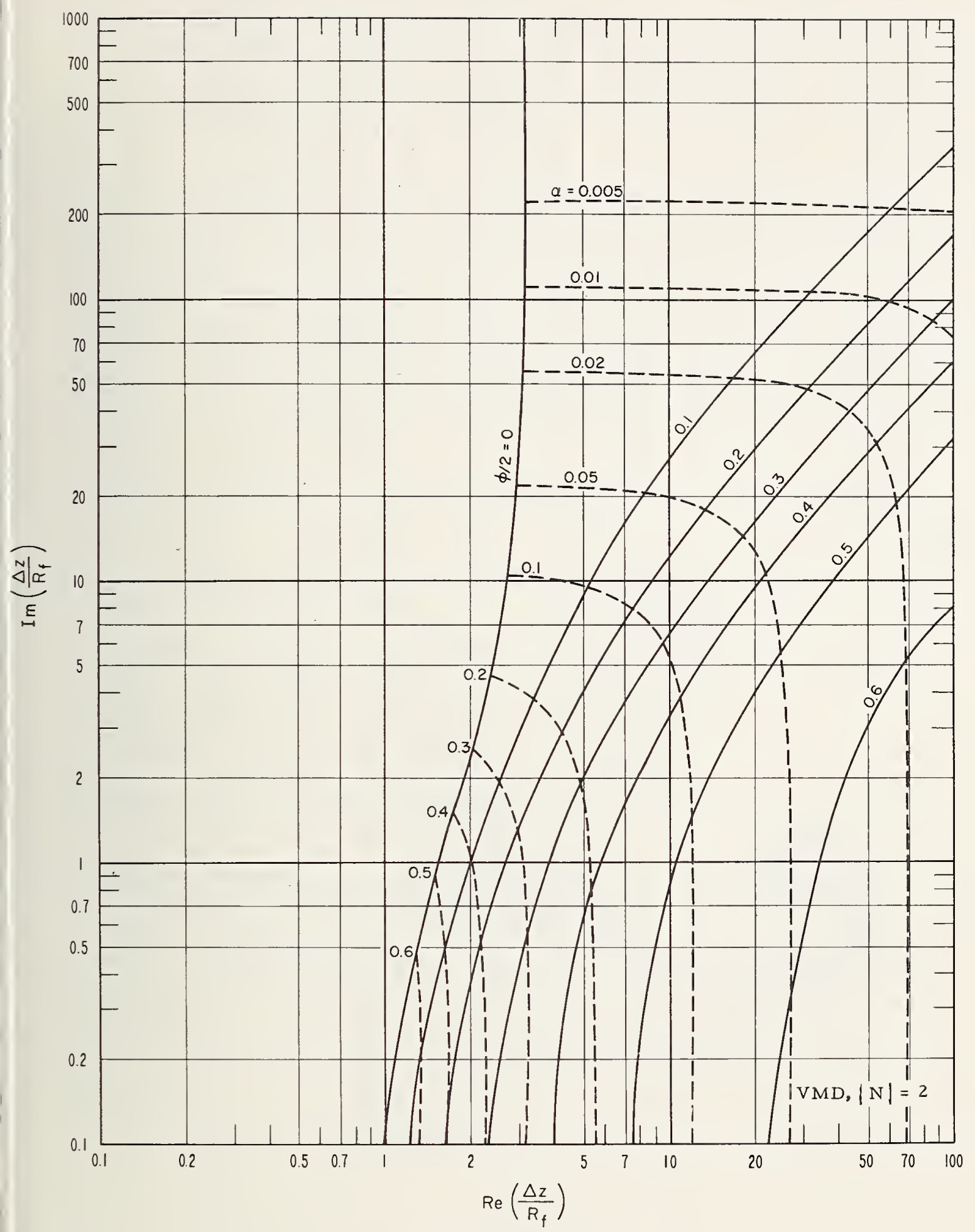

Figure 14. 


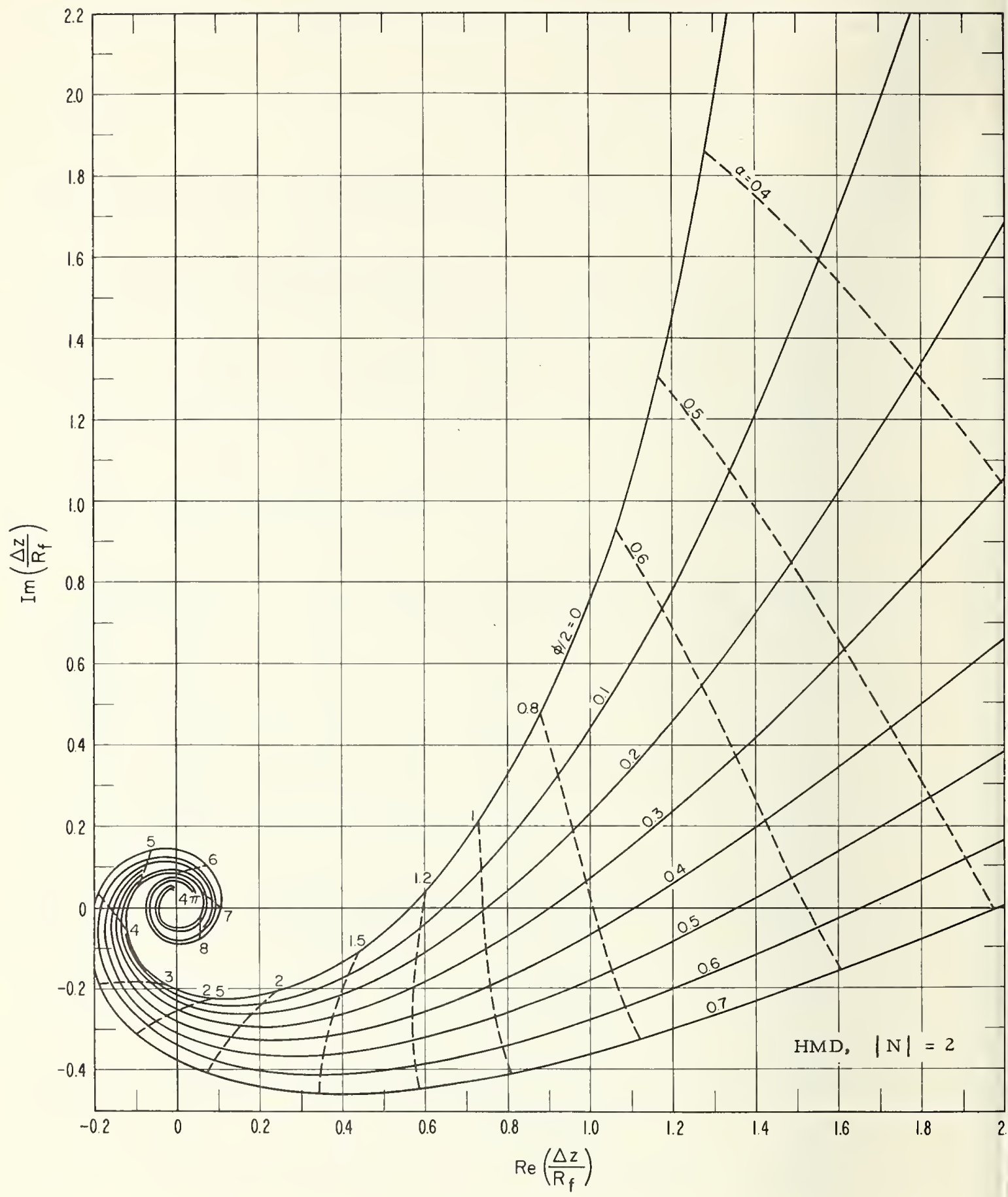

Figure 15. 


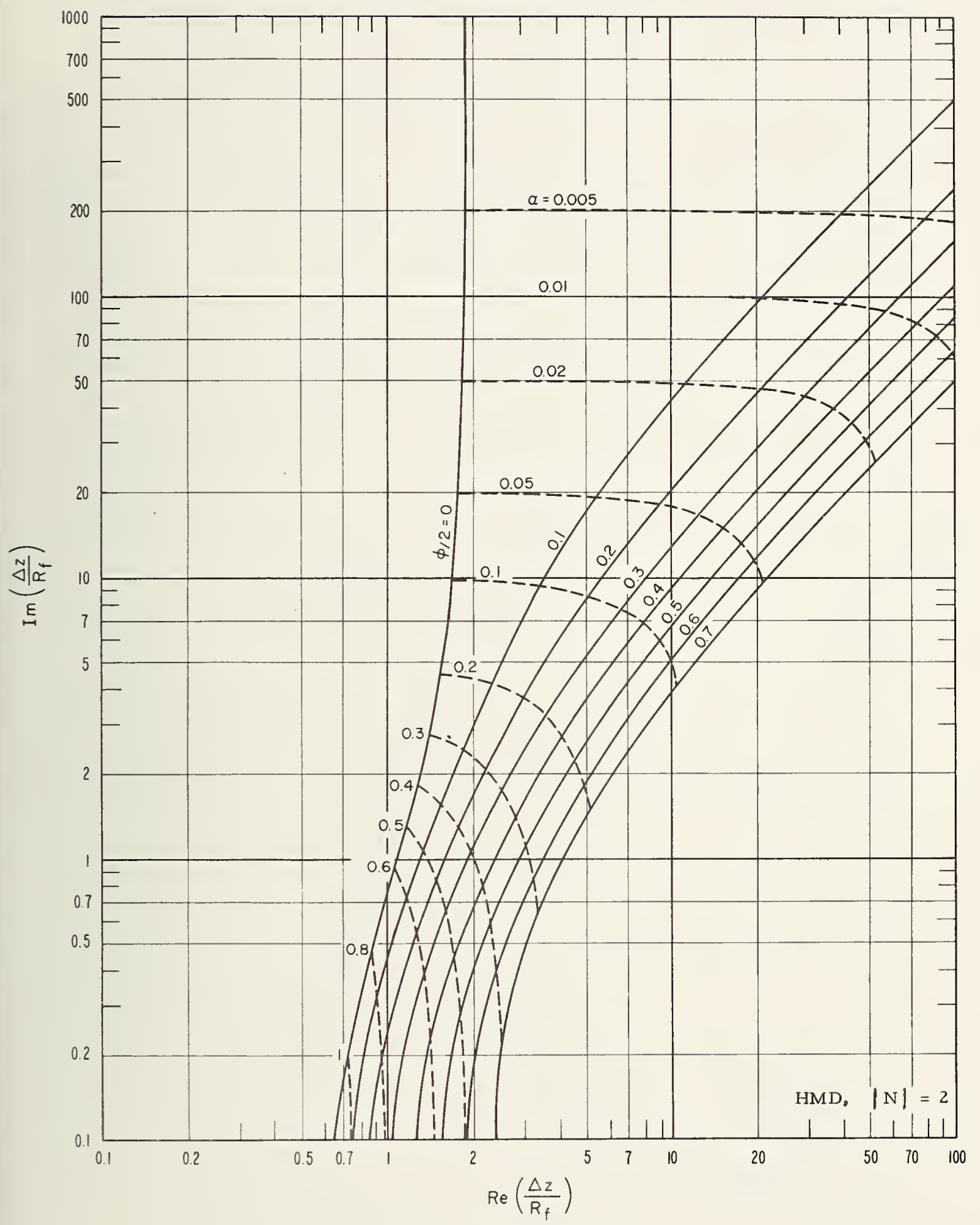

Figure 16. 


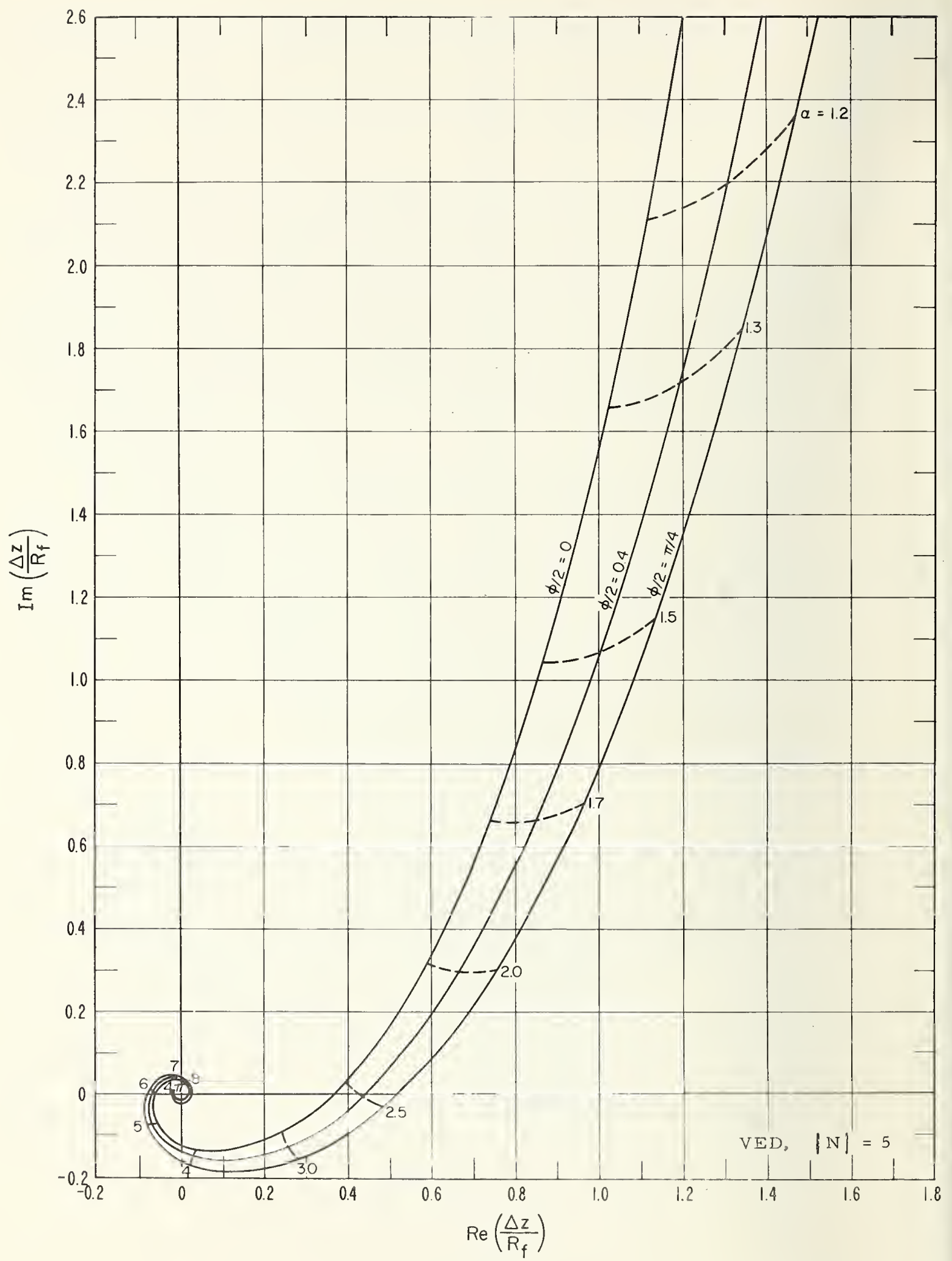

Figure 17. 


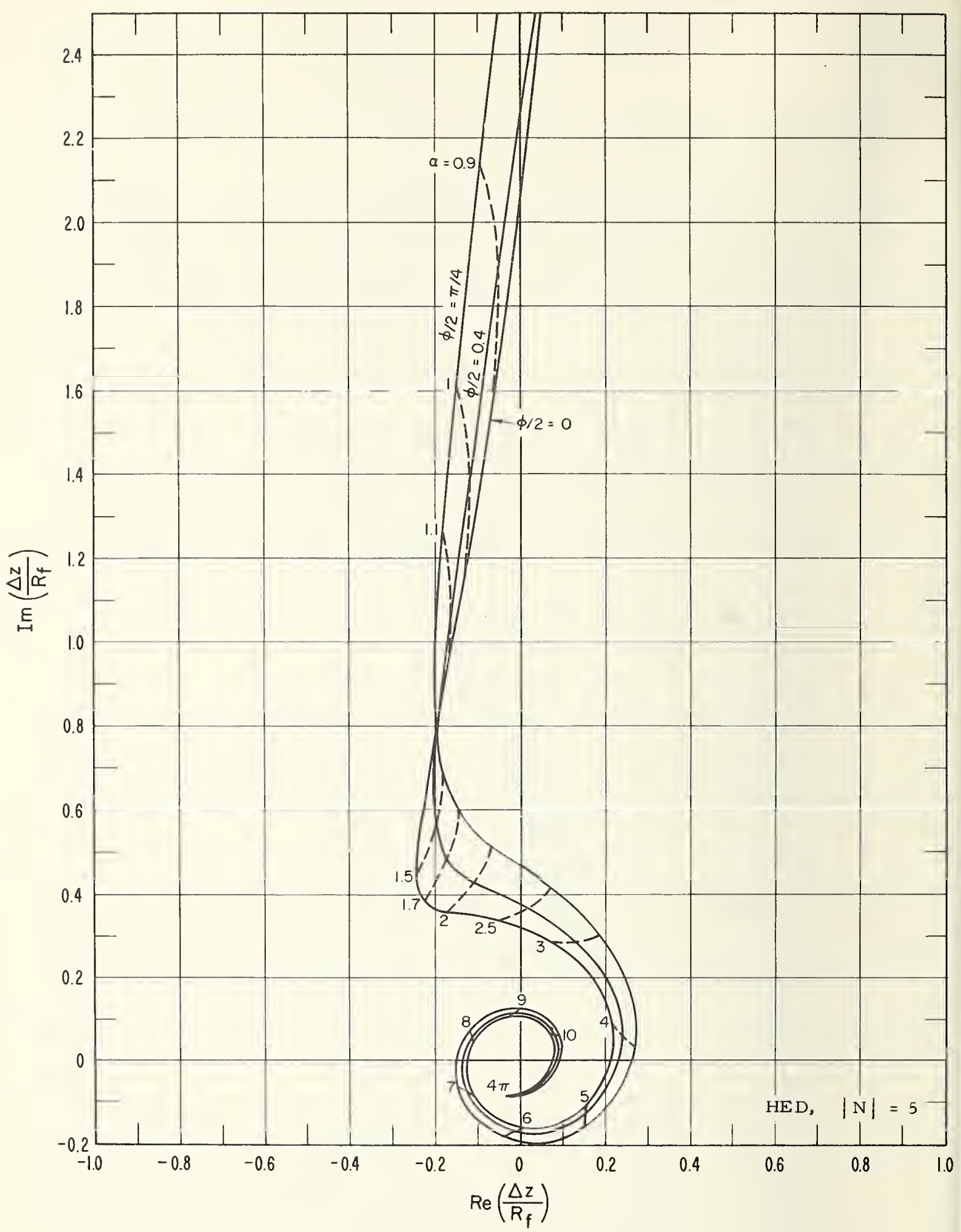

Figure 19. 


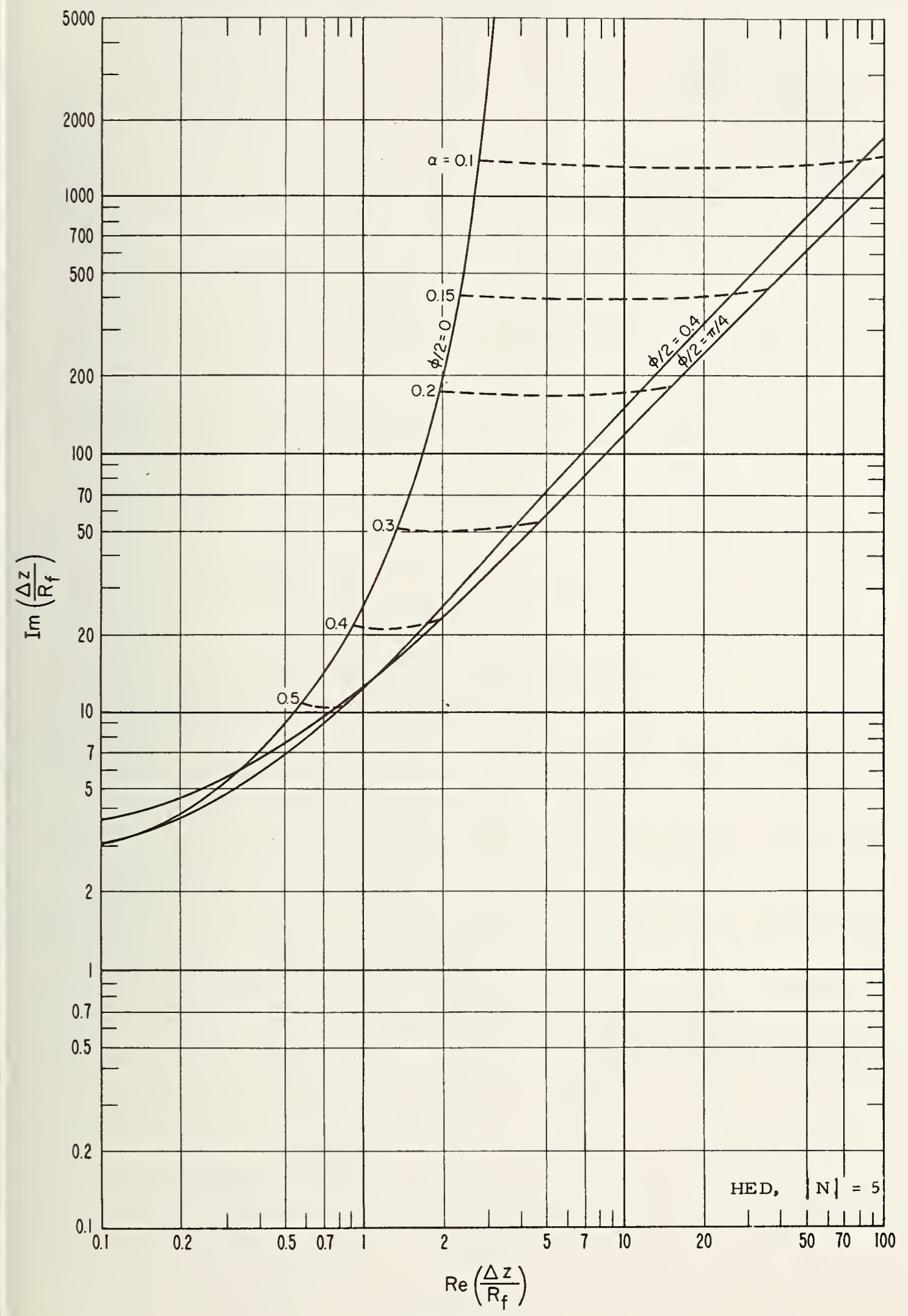

Figure 20。 


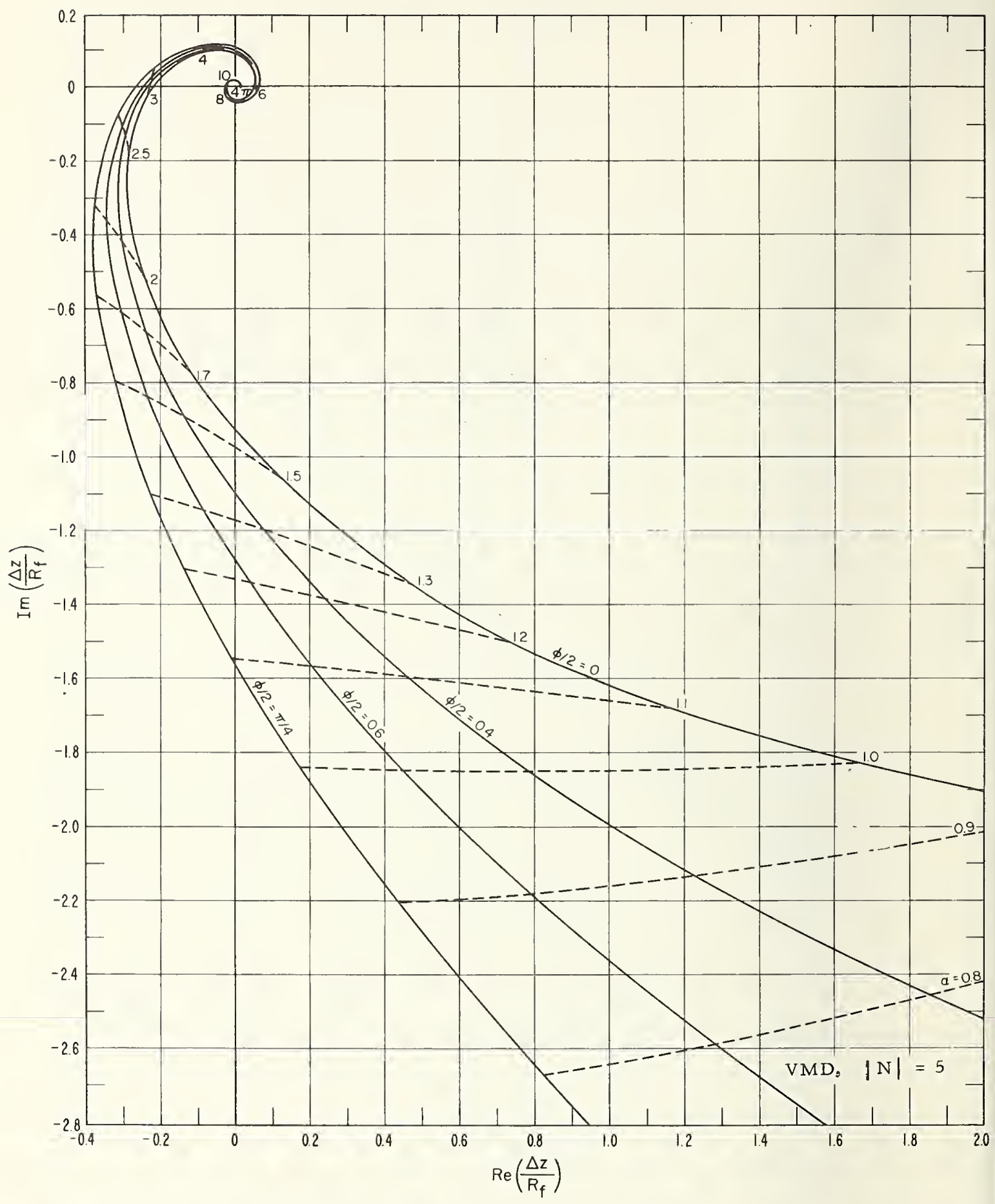

Figure 21. 


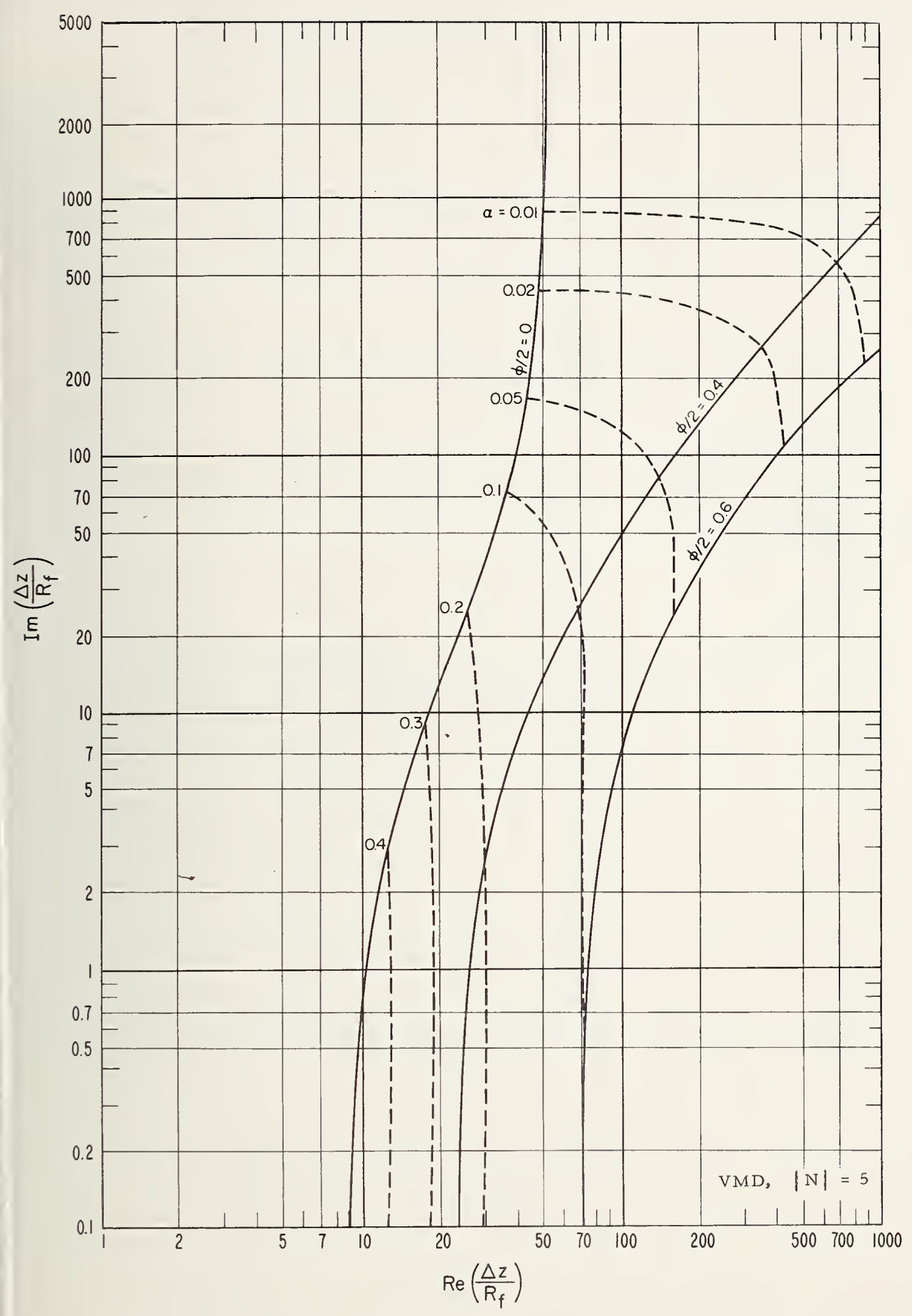

Figure 22. 


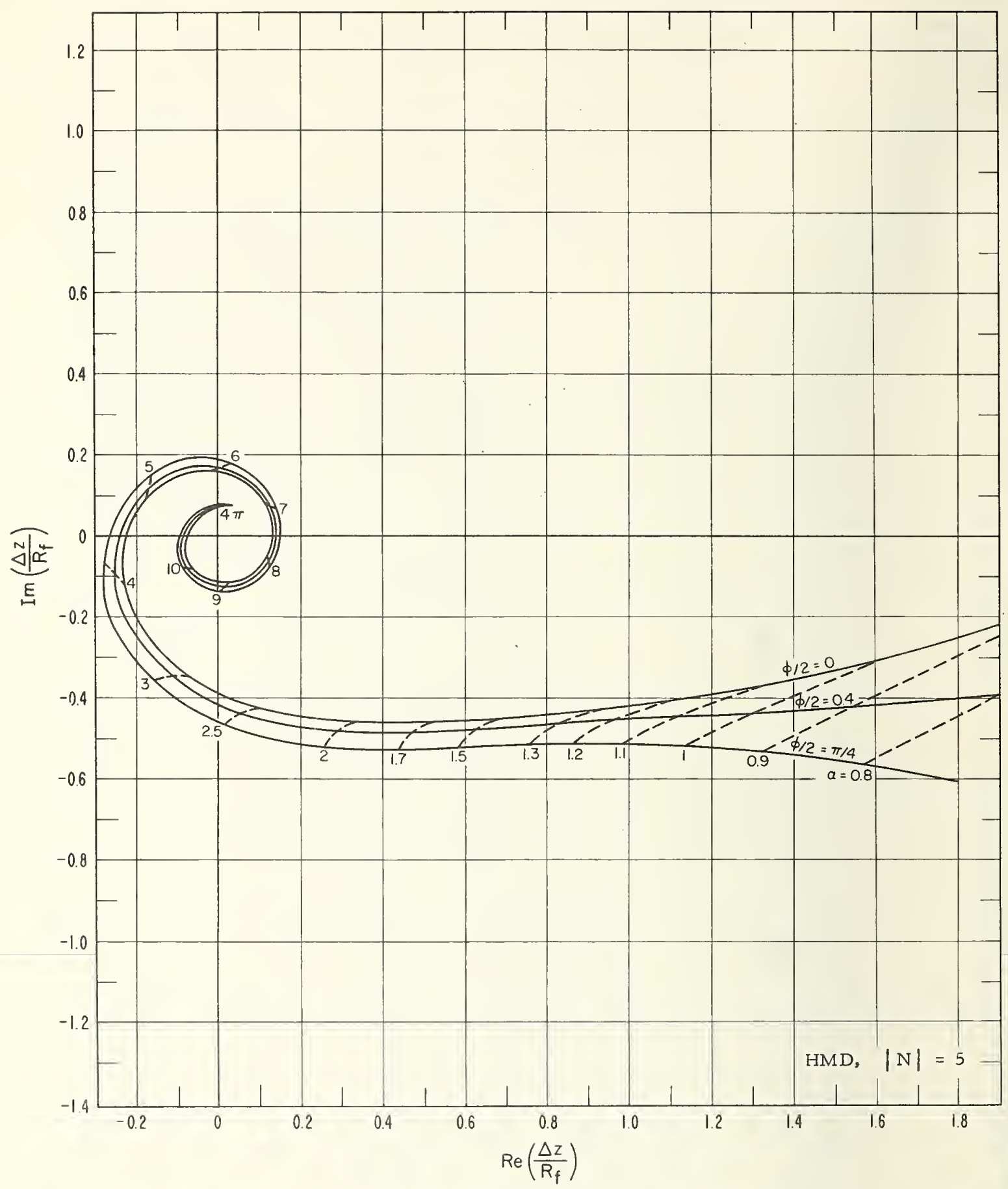

Figure 23. 


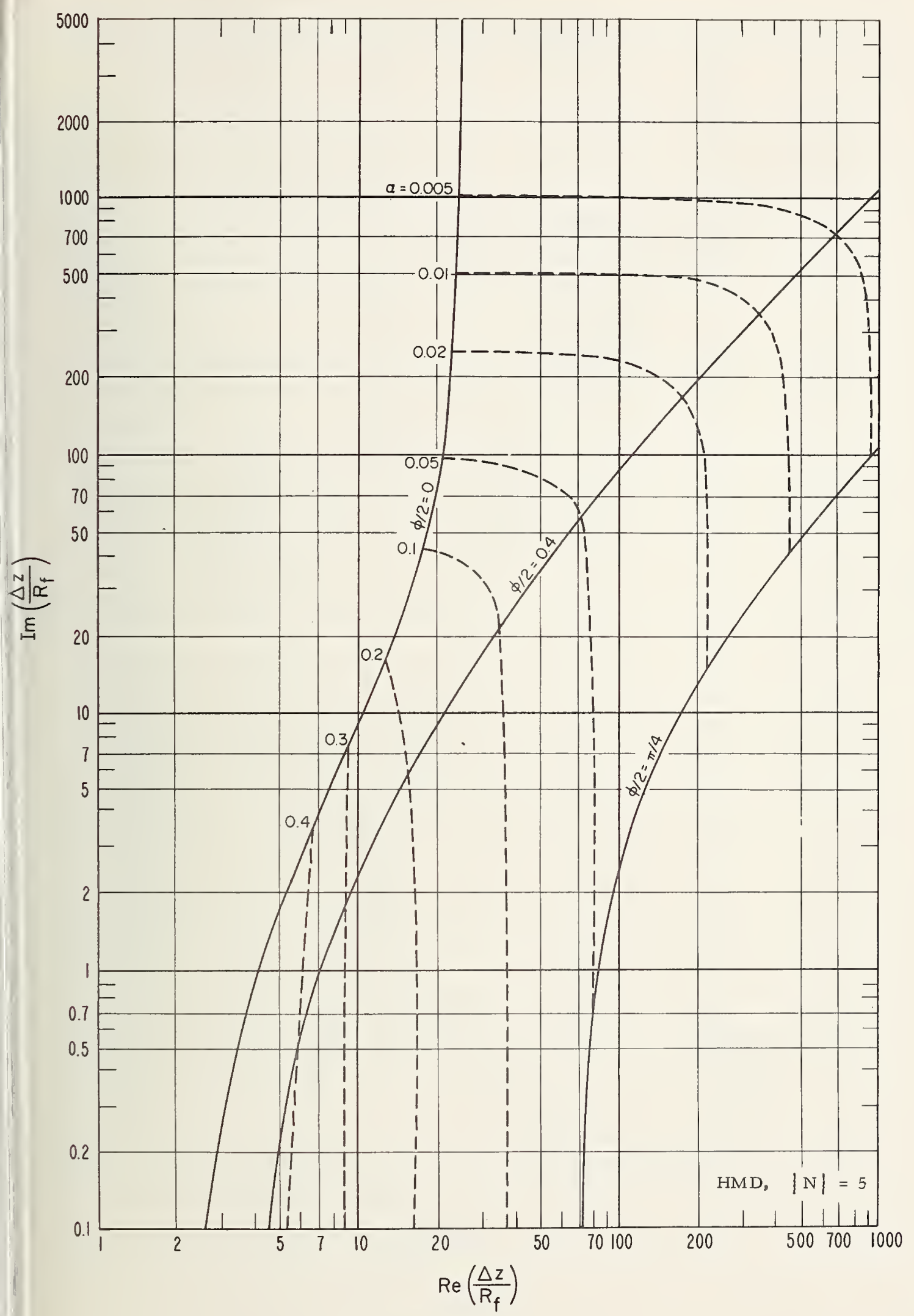

Figure 24。 


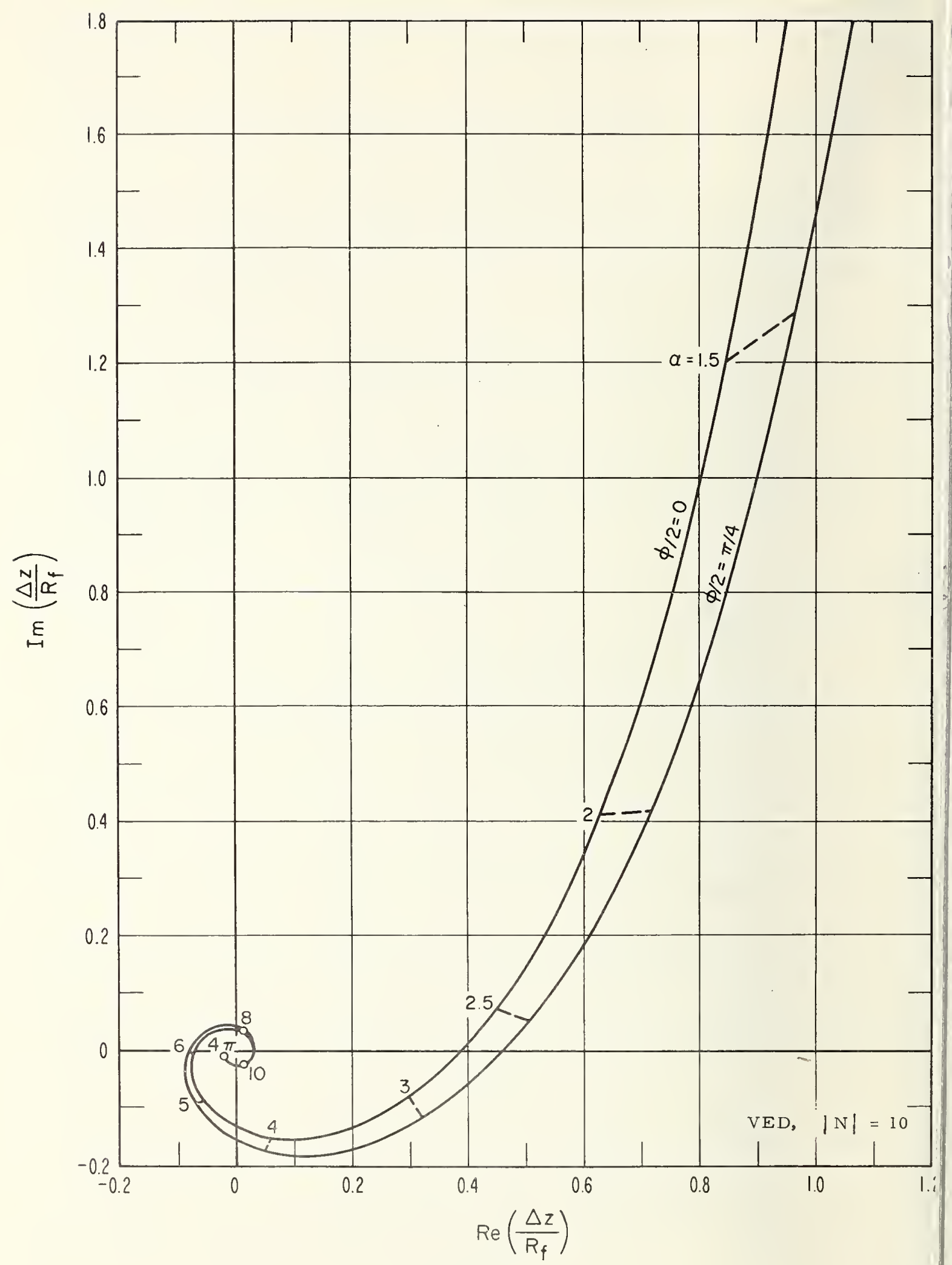

Figure 25 . 


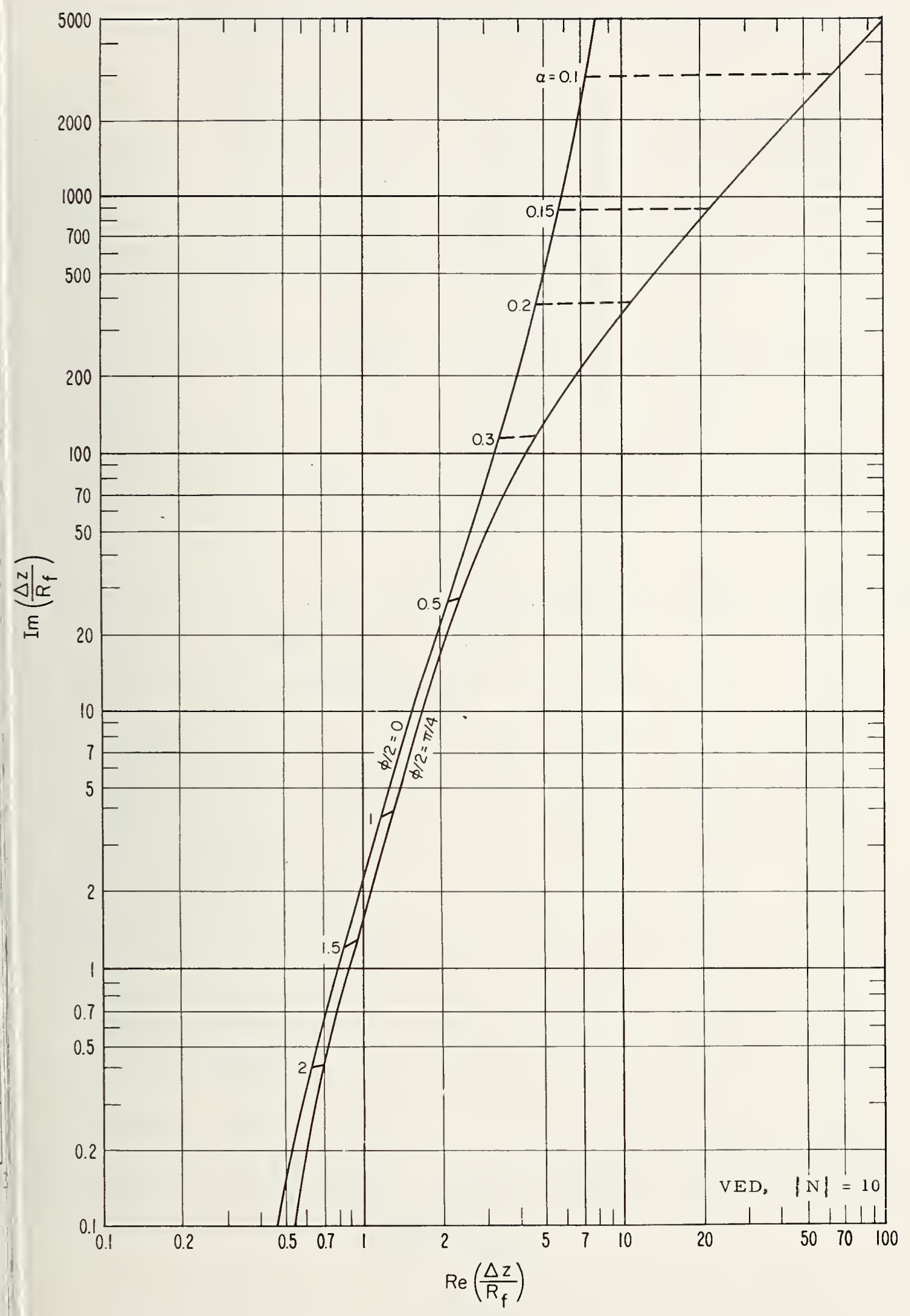

Figure 26。 


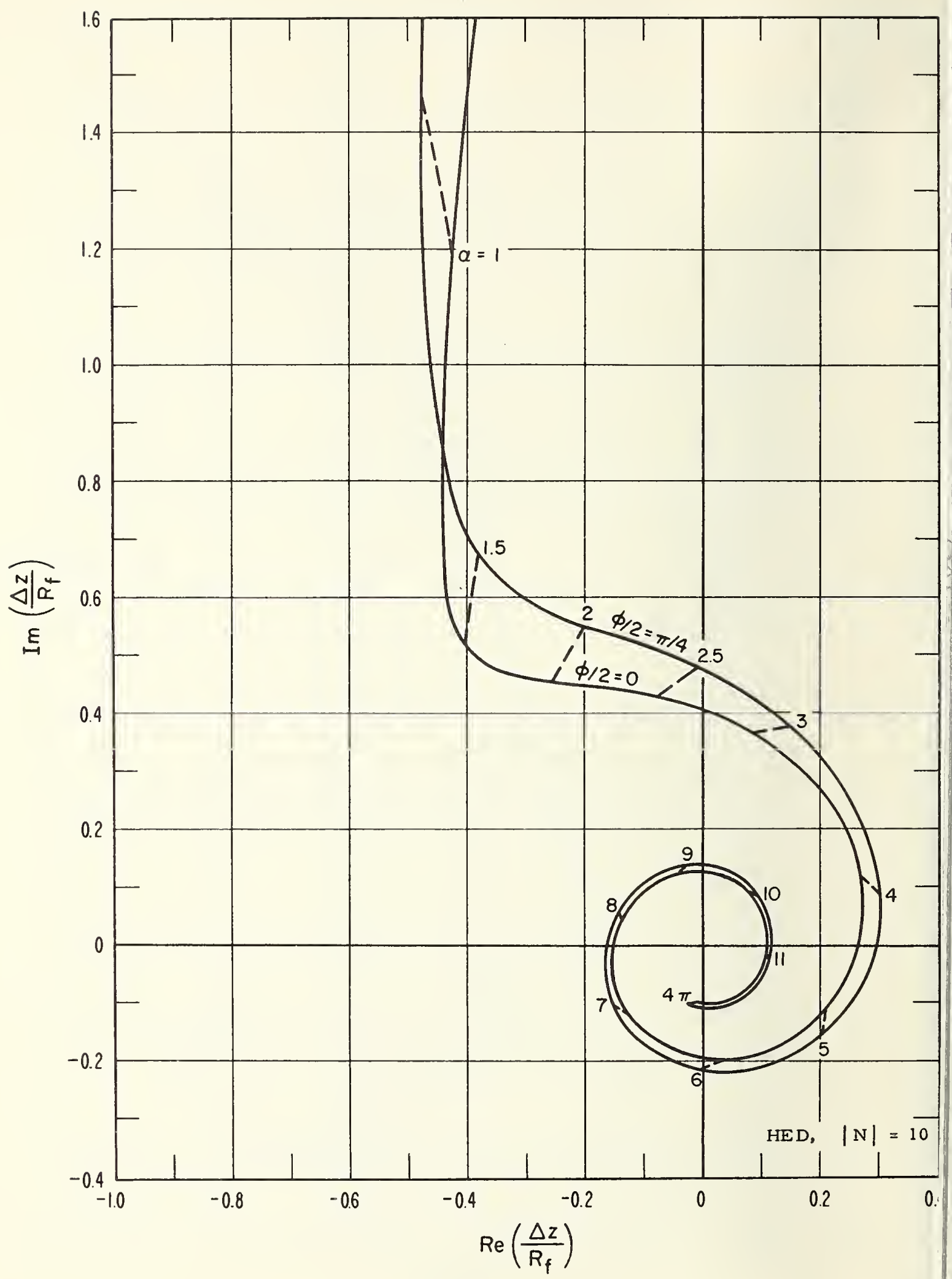

Figure 27. 


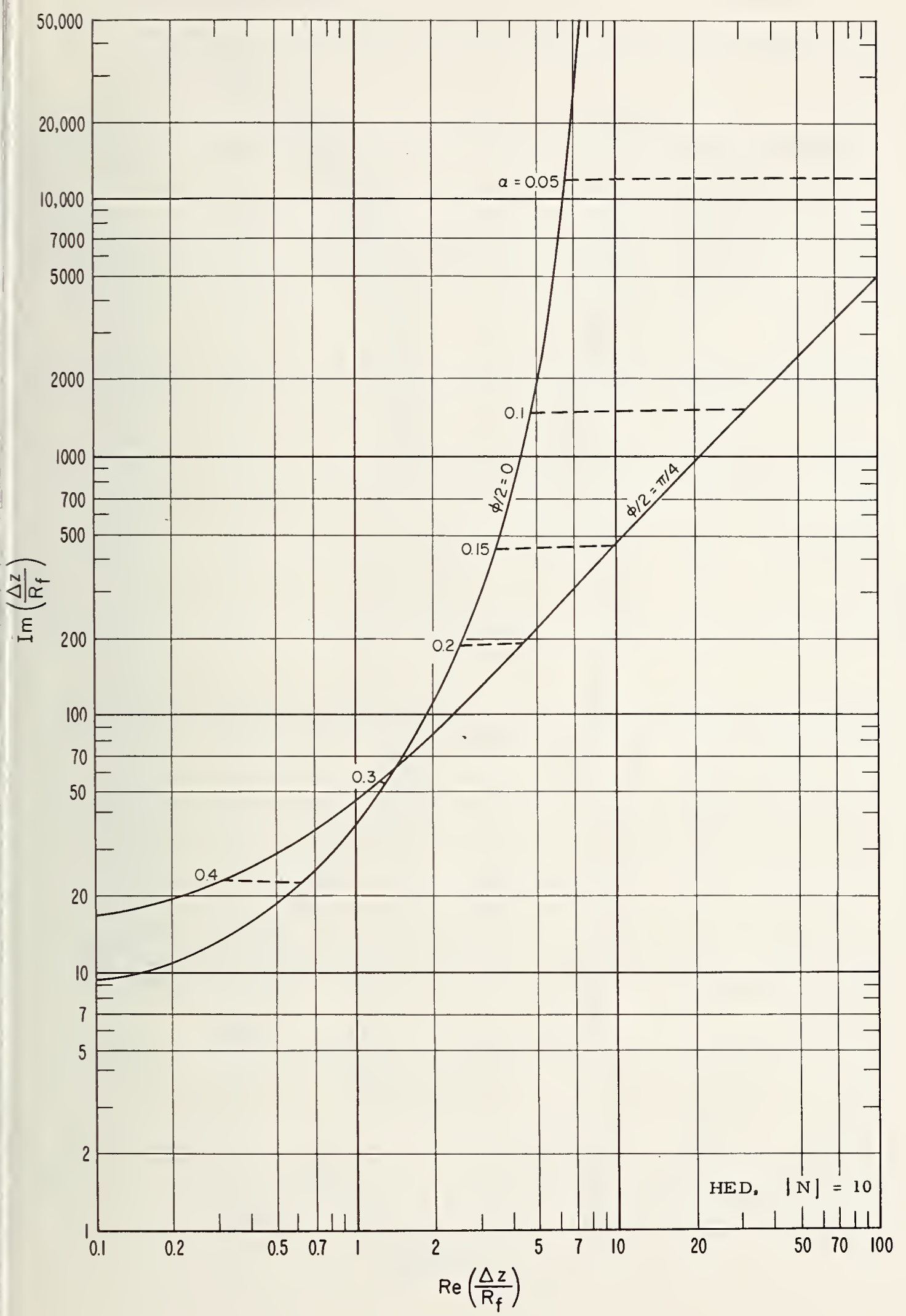

Figure 28. 


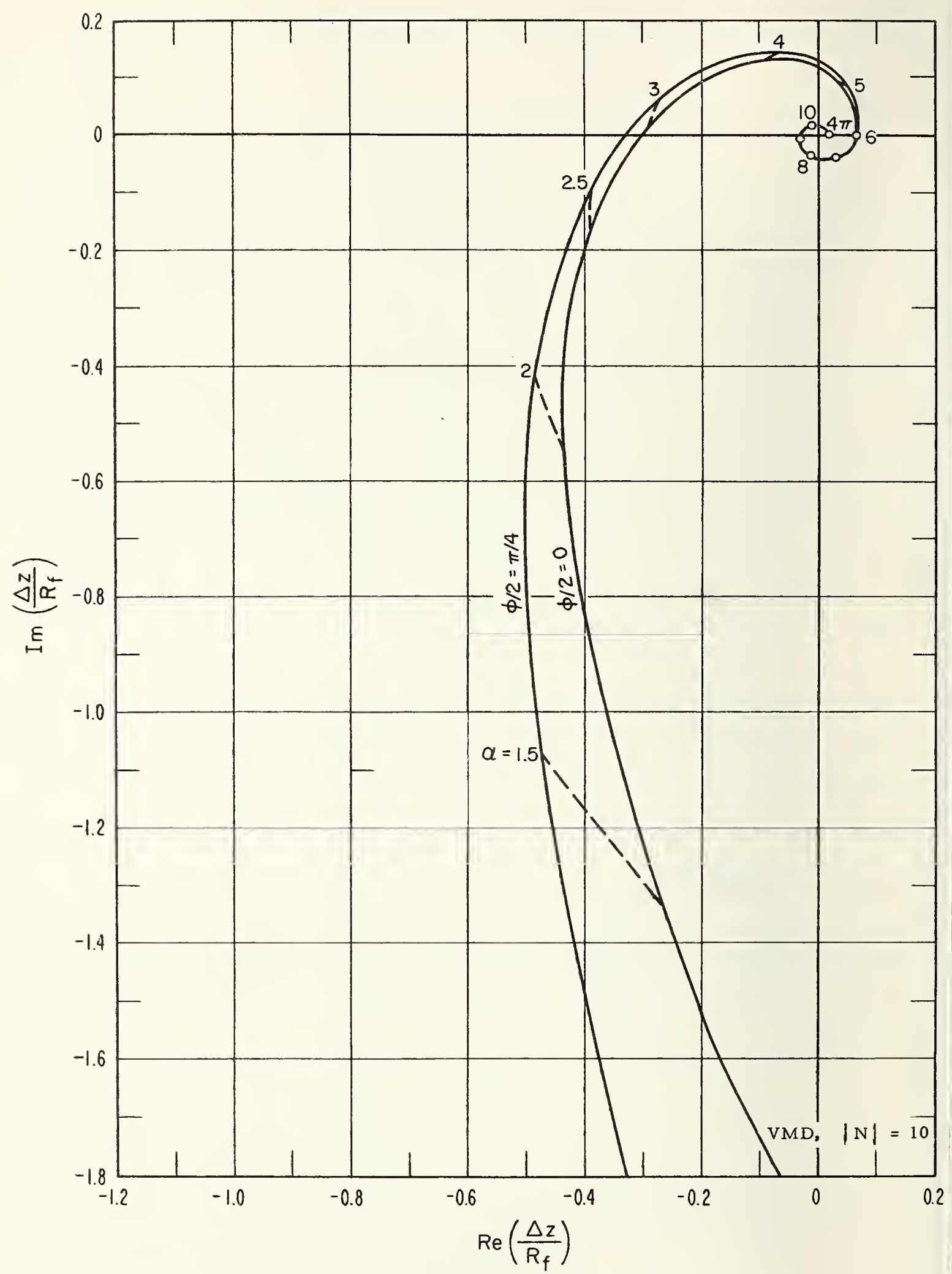

Figure 29. 


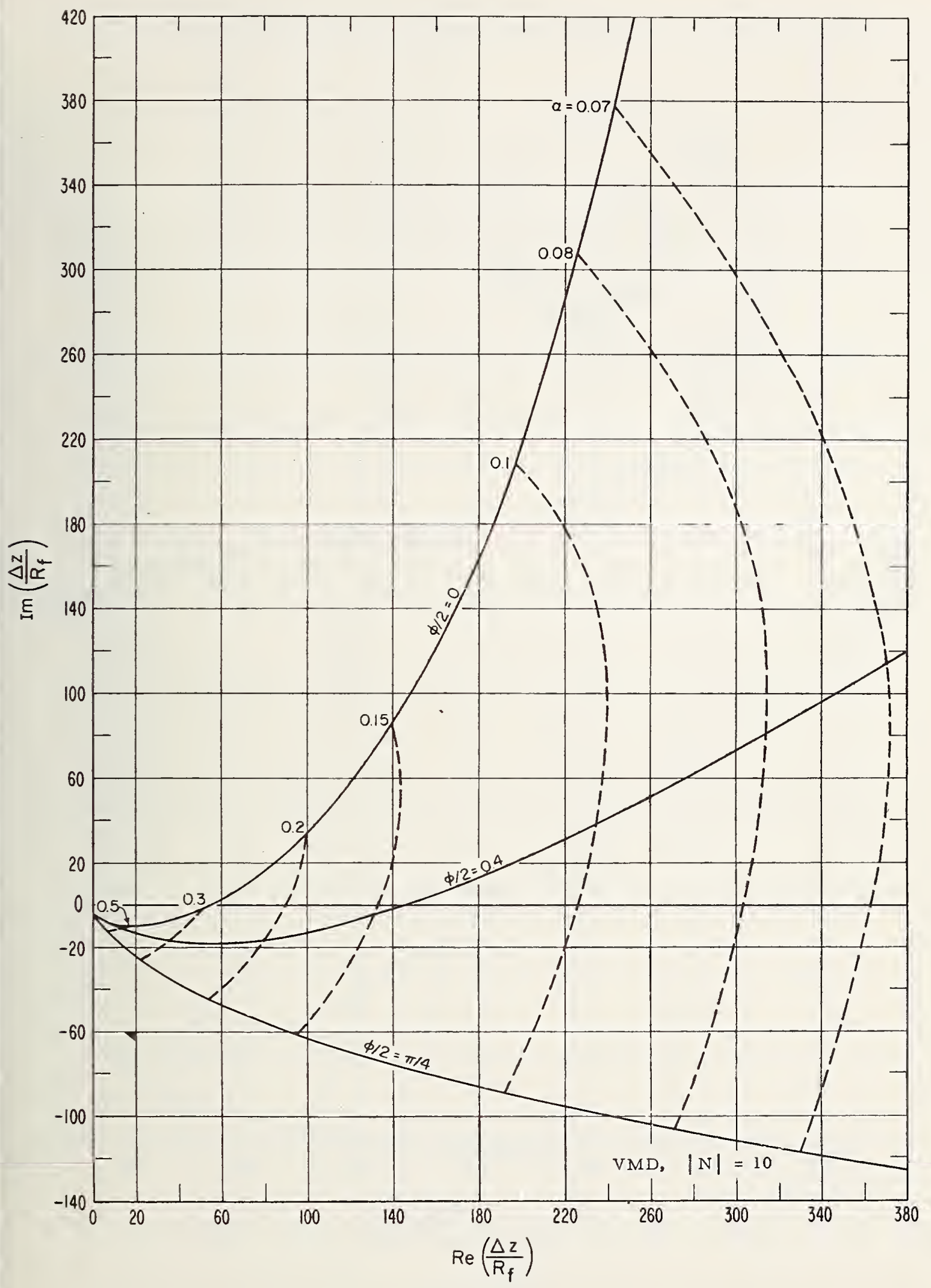

Figure 30 . 


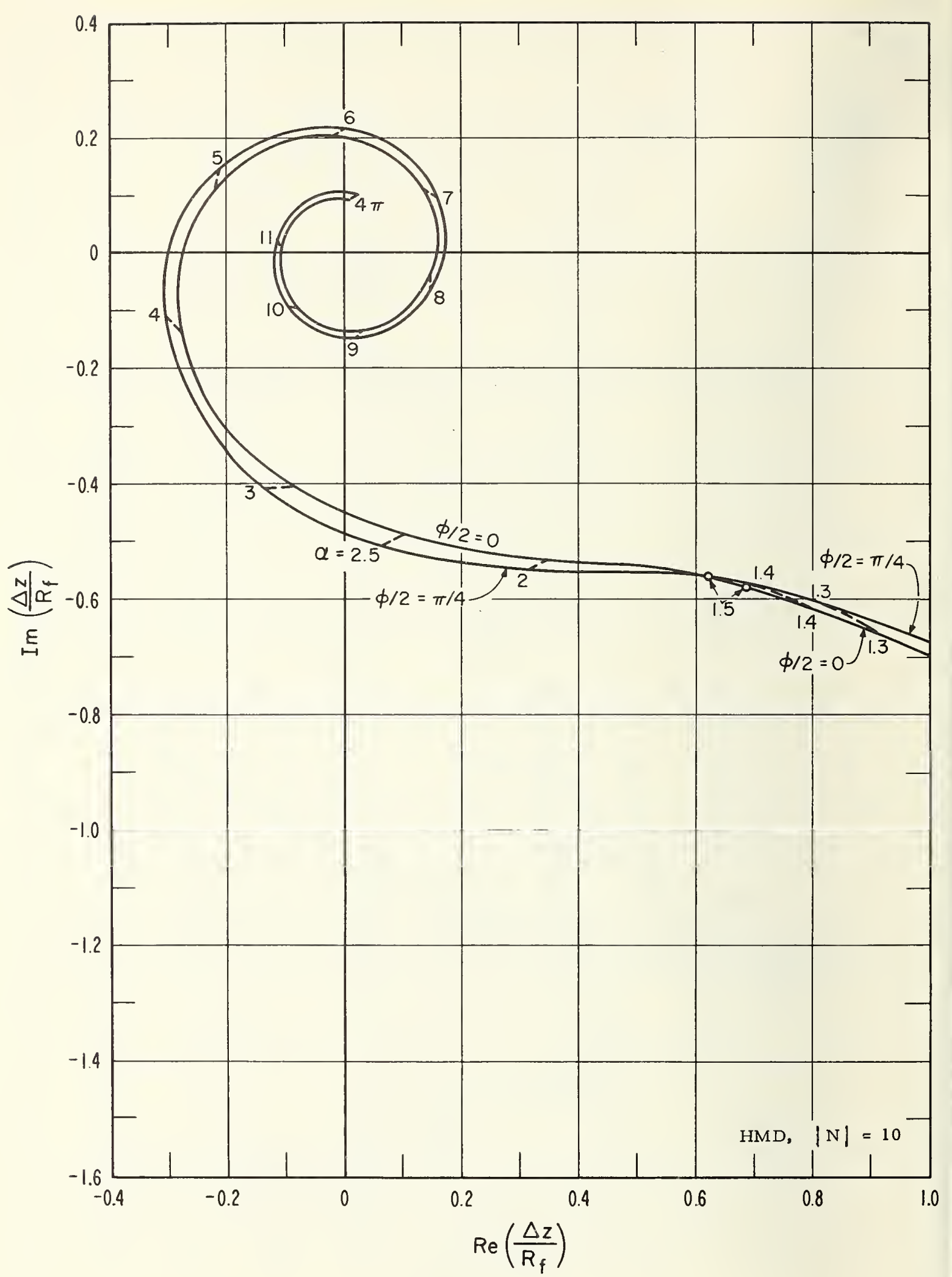

Figure 31. 


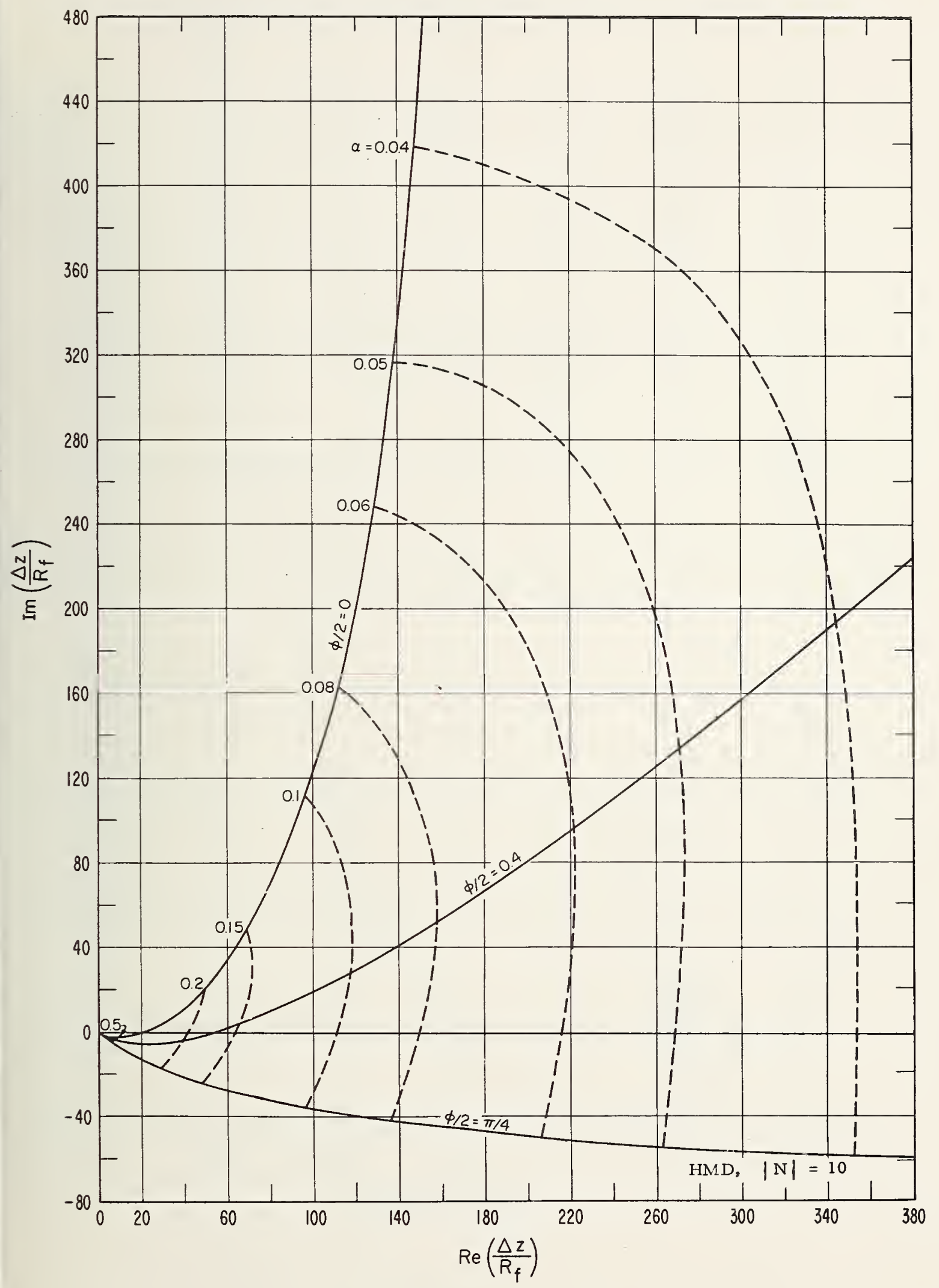

Figure 32. 


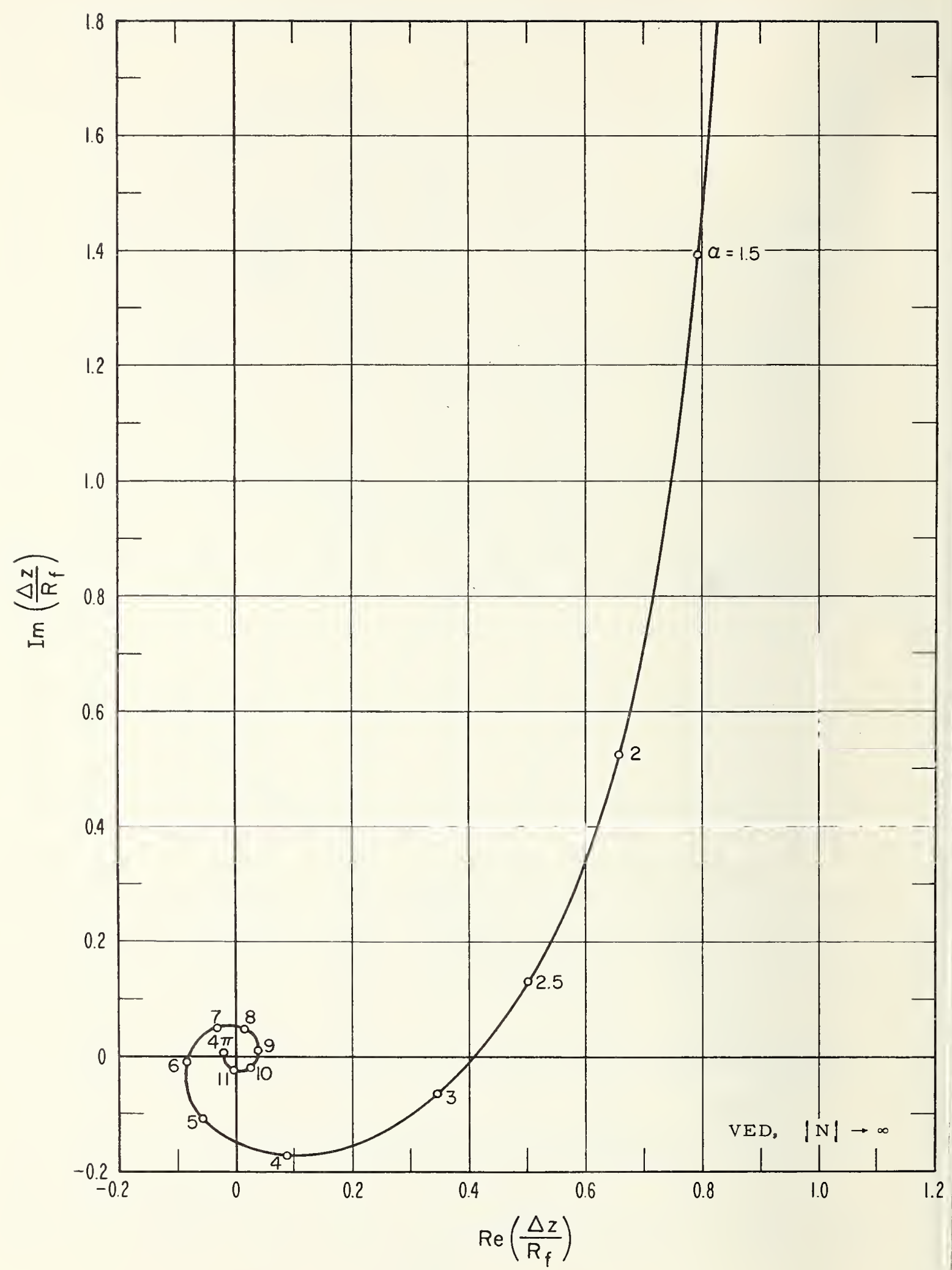

Figure 33. 


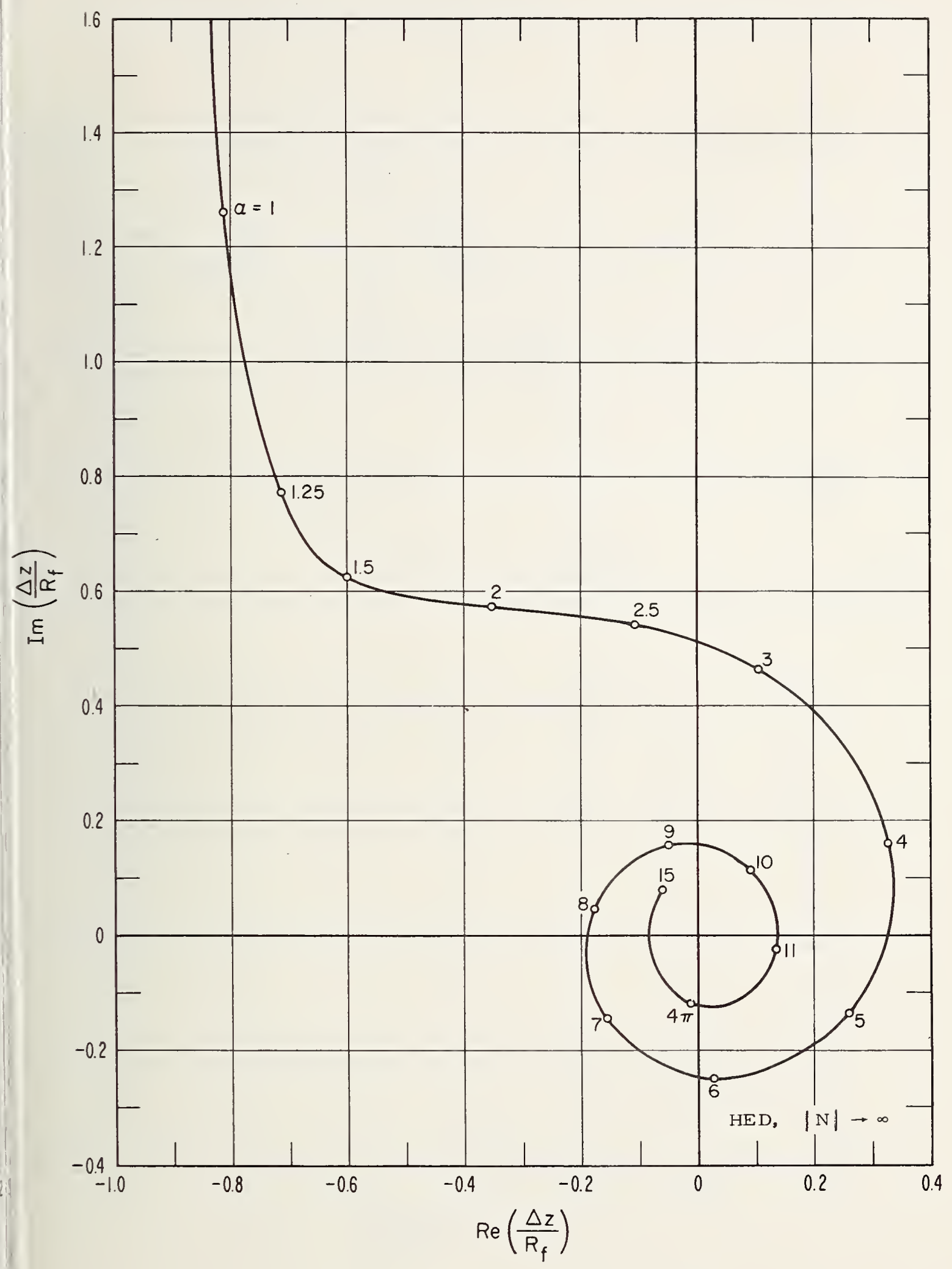

Figure 34 . 


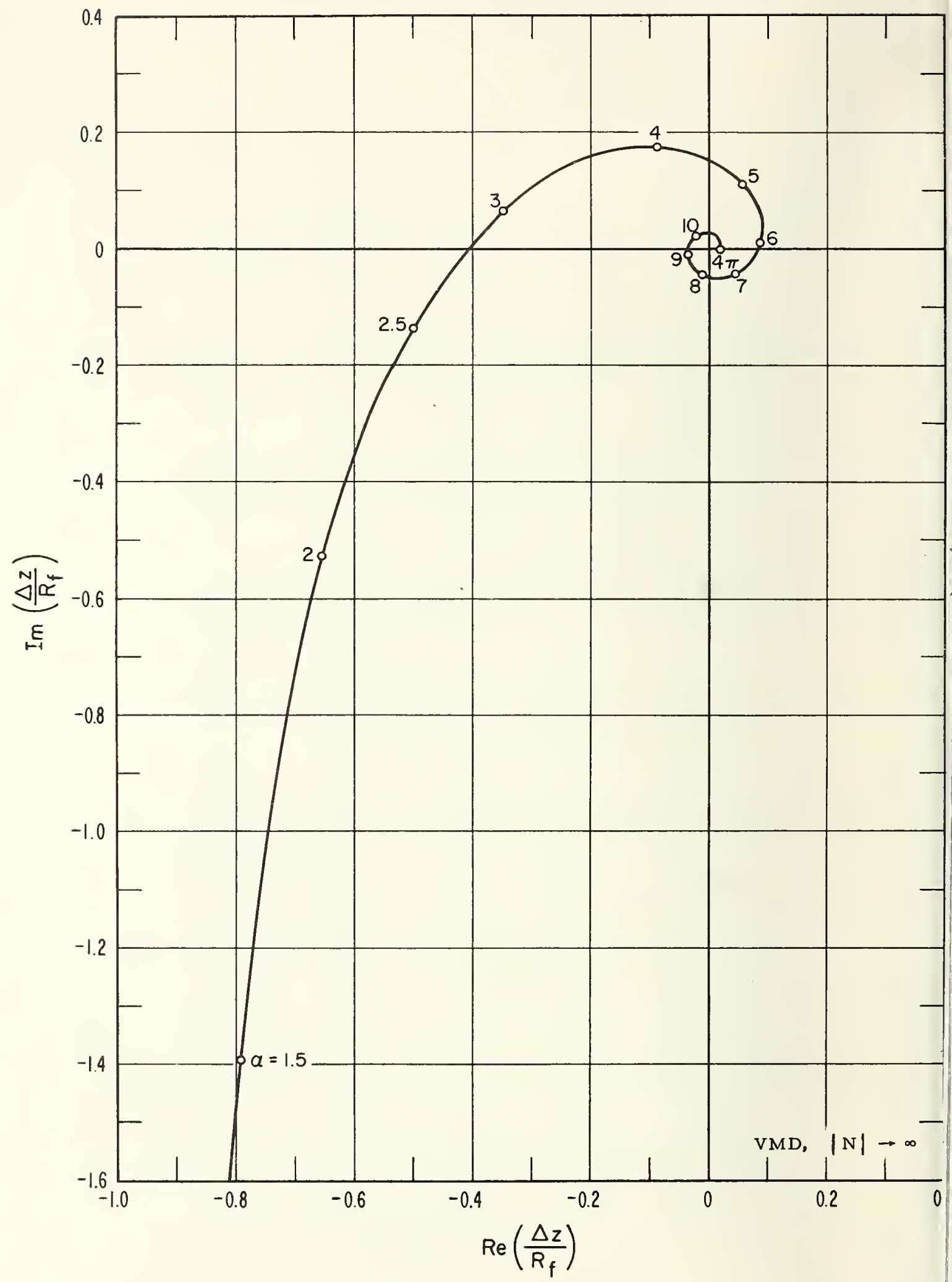

Figure 35. 


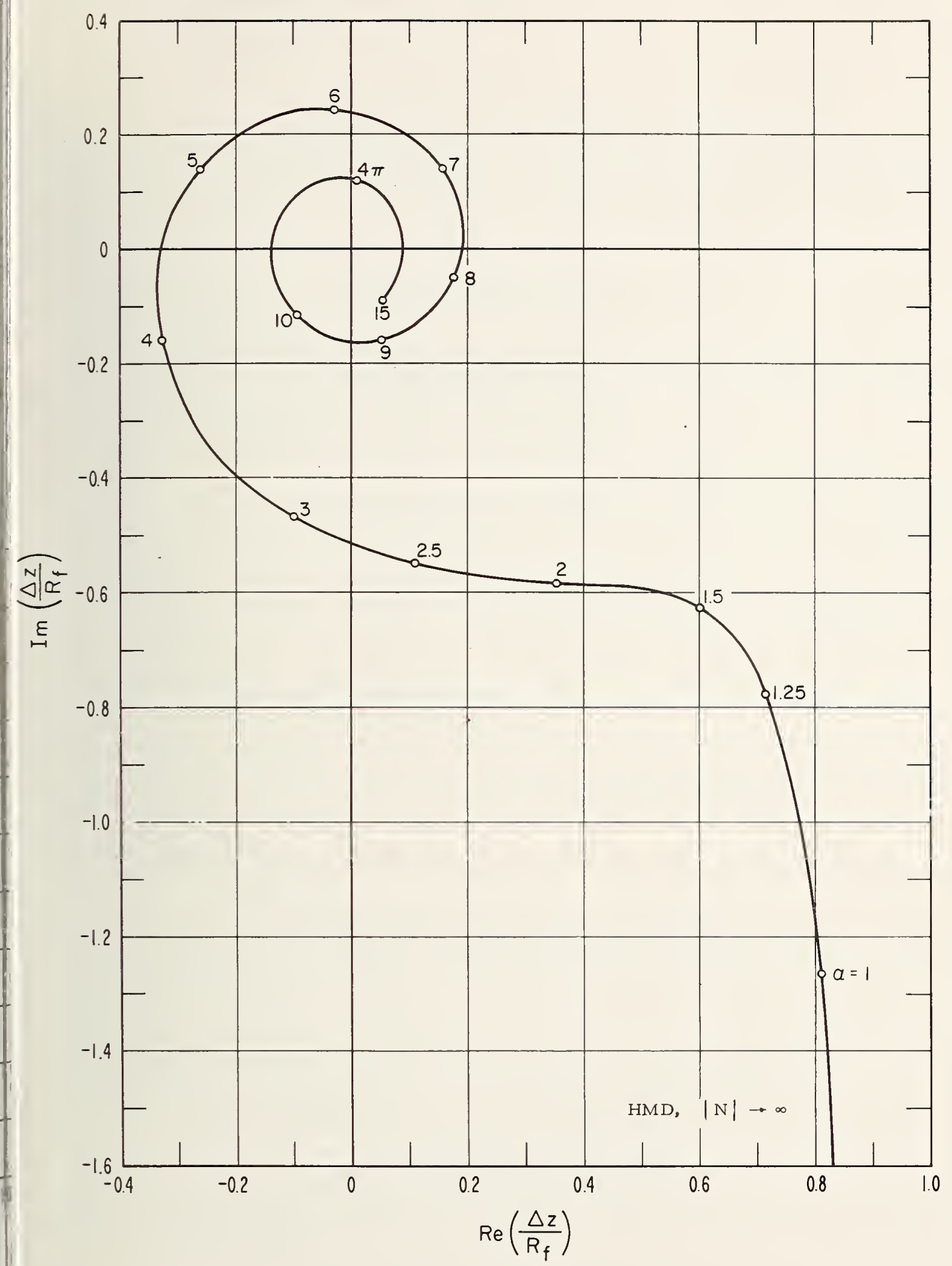

Figure 36. 



\section{THE NATIONAL BUREAU OF STANDARDS}

The scope of activities of the National Bureau of Standards at its major laboratories in Washington, D.C., and Boulder, Colorado, is suggested in the following listing of the divisions and sections engaged in technical work. In general, each section carries out specialized research, development, and engineering in the field indicated by its title. A brief description of the activities, and of the resultant publications, appears on the inside of the front cover.

\section{WASHINGTON, D.C.}

Electricity. Resistance and Reactance. Eiectrochemistry. Electrical Instruments. Magnetic Measurements. Dielectrics. High Voltage. Absolute Electrical Measurements.

Metrology. Photometry and Colorimetry. Refractometry. Photographic Research. Length. Engineering Metrology. Mass and Volume.

Heat. Temperature Physics. Heat Measurements. Cryogenic Physics. Equation of State. Statistical Physics. Radiation Physics. X-ray. Radioactivity. Radiation Theory. High Energy Radiation. Radiological Equipment. Nucleonic Instrumentation. Neutron Physics.

Analytical and Inorganic Chemistry. Pure Substances. Spectrochemistry. Solution Chemistry. Standard Reference Materials. Applied Analytical Research. Crystal Chemistry.

Mechanics. Sound. Pressure and Vacuum. Fluid Mechanics. Engineering Mechanics. Rheology. Combustion Controls.

Polymers. Macromolecules: Synthesis and Structure. Polymer Chemistry. Polymer Physics. Polymer Characterization. Polymer Evaluation and Testing. Applied Polymer Standards and Research. Dental Research.

Metallurgy. Engineering Metallurgy. Metal Reactions. Metal Physics. Electrolysis and Metal Deposition. Inorganic Solids. Engineering Ceramics. Glass. Solid State Chemistry. Crystal Growth. Physical Properties. Crystallography.

Building Research. Structural Engineering. Fire Research. Mechanical Systems. Organic Building Materials. Codes and Safety Standards. Heat Transfer. Inorganic Building Materials. Metallic Building Materials.

Applied Mathematics. Numerical Analysis. Computation. Statistical Engineering. Mathematical Physics. Operations Research.

Data Processing Systems. Components and Techniques. Computer Technology. Measurements Automation. Engineering Applications. Systems Analysis.

Atomic Physics. Spectroscopy. Infrared Spectroscopy. Far Ultraviolet Physics. Solid State Physics. Electron Physics. Atomic Physics. Plasma Spectroscopy.

Instrumentation. Engineering Electronics. Electron Devices. Electronic Instrumentation. Mechanical Instruments. Basic Instrumentation.

Physical Chemistry. Thermochemistry. Surface Chemistry. Organic Chemistry. Molecular Spectroscopy. Elementary Processes. Mass Spectrometry. Photochemistry and Radiation Chemistry.

Office of Weights and Measures.

BOULDER, COLO.

Cryogenic Engineering Laboratory. Cryogenic Processes. Cryogenic Properties of Solids. Cryogenic Technical Services. Properties of Cryogenic Fluids.

\section{CENTRAL RADIO PROPAGATION LABORATORY}

lonosphere Research and Propagation. Low Frequency and Very Low Frequency Research. Ionosphere Research. Prediction Services. Sun-Earth Relationships. Field Engineering. Radio Warning Services. Vertical Soundings Research.

Troposphere and Space Telecommunications. Data Reduction Instrumentation. Radio Noise. Tropospheric Measurements. Tropospheric Analysis. Spectrum Utilization Research. IRadio-Meteorology. Lower Atmosphere Physics.

Radio Systems. Applied Electromagnetic Theory. High Frequency and Very High Frequeney Research. Frequency Utilization. Modulation Research. Antenna Research. Radiodetermination.

Upper Atmosphere and Space Physics. Upper Atmosphere and Plasma Physics. High Latitude Ionosphere Physics. Ionosphere and Exosphere Seatter. Airglow and Aurora. Ionospheric Radio Astronomy.

\section{RADIO STANDARDS LABORATORY}

Radio Standards Physics. Frequency and Time Disseminations. Radio and Microwave Materials. Atomic Frequency and Time-Interval Standards. Radio Plasma. Microwave Physics.

Radio Standards Engineering. High Frequency Electrical Standards. High Frequency Calibration Services. High Frequency Impedance Standards. Microwave Calibration Services. Microwave Circuit Standards. Low Frequency Calibration Services. 
